\title{
Material Removal Rate, Electrode Wear Rate, and Surface Roughness Evaluation in Die Sinking EDM with Hollow Tool through Response Surface Methodology
}

\author{
Teepu Sultan, Anish Kumar, and Rahul Dev Gupta \\ Department of Mechanical Engineering, M. M. University, Mullana, Ambala, Haryana 133203, India \\ Correspondence should be addressed to Anish Kumar; anish_kaushik@rediffmail.com
}

Received 15 May 2014; Accepted 25 August 2014; Published 23 September 2014

Academic Editor: Gilles Dessein

Copyright (c) 2014 Teepu Sultan et al. This is an open access article distributed under the Creative Commons Attribution License, which permits unrestricted use, distribution, and reproduction in any medium, provided the original work is properly cited.

\begin{abstract}
Electrical discharge machining is one of the earliest nontraditional machining, extensively used in industry for processing of parts having unusual profiles with reasonable precision. In the present work, an attempt has been made to model material removal rate, electrode wear rate, and surface roughness through response surface methodology in a die sinking EDM process. The optimization was performed in two steps using one factor at a time for preliminary evaluation and a Box-Behnken design involving three variables with three levels for determination of the critical experimental conditions. Pulse on time, pulse off time, and peak current were changed during the tests, while a copper electrode having tubular cross section was employed to machine through holes on EN 353 steel alloy workpiece. The results of analysis of variance indicated that the proposed mathematical models obtained can adequately describe the performances within the limits of factors being studied. The experimental and predicted values were in a good agreement. Surface topography is revealed with the help of scanning electron microscope micrographs.
\end{abstract}

\section{Introduction}

Electrodischarge machining is a nonconventional machining process extensively used in industry for processing of parts having unusual profiles with reasonable precision [1]. Steel is a widely used engineering material. There are a variety of steels used for numerous applications. The steel is being divided into low carbon, medium carbon, and high carbon steel on the basis of carbon content. Low carbon steel contains a carbon content from $0.15 \%$ to $0.45 \%$. It is the most common form of steel as it provides material properties that are acceptable for many applications [2]. EN 353 steel is cheaply available and widely used alloy. EN 353 is low alloy case carburized steel, predominantly used for manufacturing heavyduty gears, shafts, pinions, and especially crown wheel [3].

Discharge current was the most significant controlling parameter in machining $\mathrm{Al}-15 \% \mathrm{SiC}$ MMC using multihole electrode by grey relational analysis, while Taguchi method was employed to determine the relations between the machining parameters and process characteristics like MRR (material removal rate), EWR (electrode wear rate), and SR (surface roughness) [4]. The combination of maximum pulse on time and minimum pulse off time gives maximum MRR on Al-7075 alloy with brass electrode using Taguchi approach [5]. Amorim and Weingaertner concluded that the best results of MRR and surface texture for duty factor of 0.5 were obtained with tungsten-copper electrodes, no matter the machining conditions while machining copper-beryllium ASTM C17200 alloy [6]. Single-channel electrodes have comparatively better MRR and lower EW during fast hole drilling of Inconel 718 and Ti-6Al-4V with tubular electrodes of brass and copper, while copper electrode undergoes lower wear than brass electrode [7]. Discharge current, pulse on time and pulse off time, had a significant influence on the machining characteristics such as MRR, EWR, and overcut while machining Inconel 718 [8] and on gap current while machining high strength low alloy steel (HSLA), respectively [9].

Kerosene decomposes at higher temperature due to larger discharge energy and produces carbon particles that adhere to the electrode surface and this phenomenon restricts rapid 
tool wear during machining than deionized water [10]. Globules of debris, pockmarks, and melted drops were observed on the surfaces of blind holes which were more dispersed and pronounced. Most significant parameters like voltage and current in the optimization of a single quality characteristic are not being significant as in multiple quality characteristics [11]. Patel et al. done the multiobjective optimization with copper electrode and concluded that lower value of parameters reduces the tool wear ratio substantially, while their higher values increase the MRR drastically on AISI tool steel [12]. MRR not only increases with increase in discharge current but also increases the microcracks density on machining tungsten carbide with graphite electrode [13]. Increasing discharge energy increases instability and, due to which, the quality of the workpiece surface becomes rougher and the white layer thickness increases. Also the amount of particles in the gap becomes too large and forms electrically conducting paths between the tool electrode and the workpiece causing unwanted discharges, which becoming electric arcs (arcing). These electric arcs damage the electrodes surfaces (tool and workpiece surfaces) and can create microcracks [14]. During EDM processes, a significant amount of workpiece material was found to be transferred from workpiece surface to tool surface and vice versa. Also, a continuous burning of cutting fluid gives out a carbon residue, a visual black layer on machined surface, which decreases the EWR [15]. Kansal et al. reported that surface roughness of EN-31 tool steel with copper electrode gives the best surface finish if obtained at the lower level of peak current and pulse on time [16]. While increasing the pulse current or reducing the pulse on duration suppresses the formation of surface cracks in the SKD11 machined surface and hence improves the fatigue life [17]. Kumar et al. [18] revealed that intense heat conditions in the machining zone yielded higher crack densities and surface roughness while machining titanium at higher peak current along with a higher frequency of the globules of debris than on steel. Mathematical modeling of process using response surface methodology shows that the developed model can achieve reliable prediction of experimental results within acceptable accuracy [19]. Çaydaş and Hasçalik also added that RSM is an economical way for obtaining information for any system with the fewest numbers of experiments [20]. Many researchers used RSM to quantify the effect of control factors on their problems [21-24]. Box-Behnken design gives us robustness to the unavailability of data over central composite design [25]. Reversing the polarity of sparking alters the material removal phenomenon with an appreciable amount of electrode material depositing on the workpiece surface [26]. Due to its structural integrity, copper has ability to produce very fine surface finishes, even without special polishing circuits. It also makes copper electrodes highly resistant to DC arcing in poor flushing situations [27]. Rajesha et al. [1] demonstrated that hollow tool is particularly useful for drilling holes with low tool wear rate. It was found that while machining the same length of the Inconel 718 with a solid tool, it takes approximately $40 \%$ more machining time than that taken by a hollow tool. It also helps in minimizing the dielectric fluid degradation. Consequently, the approach light is cost effective with higher yield and reduced material and energy loss.

By scrutiny of the published research work, this paper addresses the issue that an alternate type of tool like hollow tube electrode may have a positive impact on MRR with low tool wear rate due to improved flushing conditions. Also there is a little work that has been carried out regarding the modelling and analysis of the EDM process on EN 353 steel alloy material with the MRR, EWR, and SR as the machining performances. In this study, mathematical models have been developed using response surface methodology, while analysis of variance (ANOVA) is used to check the validity of the models. Surface topography is revealed with the help of scanning electron microscope (SEM) micrographs.

\section{Experimental Procedure}

Experiments were conducted on a die sinking EDM machine, model Electronica Xpert $1 \mathrm{CNC}$ as shown in Figure 1(a). In this study, EN 353 steel is selected as the work material. Chemical composition of the workpiece material is given in Table 1. A cylindrical electrode with tubular section having $12 \mathrm{~mm}$ external and $9 \mathrm{~mm}$ internal diameter cooper was used as the electrode (tool). Figures 1(b) and 1(c) show a typical copper electrode used in the experimentation. Kerosene oil was used as a dielectric.

The process parameters and their levels for the main experiments were decided on the basis of the pilot experiments conducted using one-factor-at-a-time approach as shown in Table 2.

The Box-Behnken design (BBD) was used for planning and executing the subsequent main experimentation, as shown in Table 3. In this study, an effort has been made to model the empirical relationship between machining parameters by using response surface methodology. The workpiece was connected to the positive polarity while the tool electrode was maintained at negative polarity. Side flushing method was employed for the dielectric fluid. A hole depth of $8 \mathrm{~mm}$ and diameter of $12 \mathrm{~mm}$ was machined throughout, for each run. The process parameters and depth of cut were programmed in the NC controlled unit. Once the experimentation was completed, the workpieces were cleaned thoroughly using acetone and the final individual weight of electrode was measured. Material removal rate was calculated by using the following formula:

$$
\operatorname{MRR}=\frac{V\left(\mathrm{~mm}^{3}\right)}{t(\min )}\left(\mathrm{mm}^{3} / \mathrm{min}\right),
$$

where $V$ is volume of material removed and $t$ is the machining time.

Electrode wear rate was calculated by using the following formula:

$$
\mathrm{EWR}=\frac{E_{b}-E_{a}(\mathrm{~g})}{t(\mathrm{~min}) * \text { density }\left(\mathrm{g} / \mathrm{mm}^{3}\right)}\left(\mathrm{mm}^{3} / \mathrm{min}\right),
$$

where $E_{b}$ and $E_{a}$ are the weights of electrode material before and after machining, respectively, and $t$ is the machining 


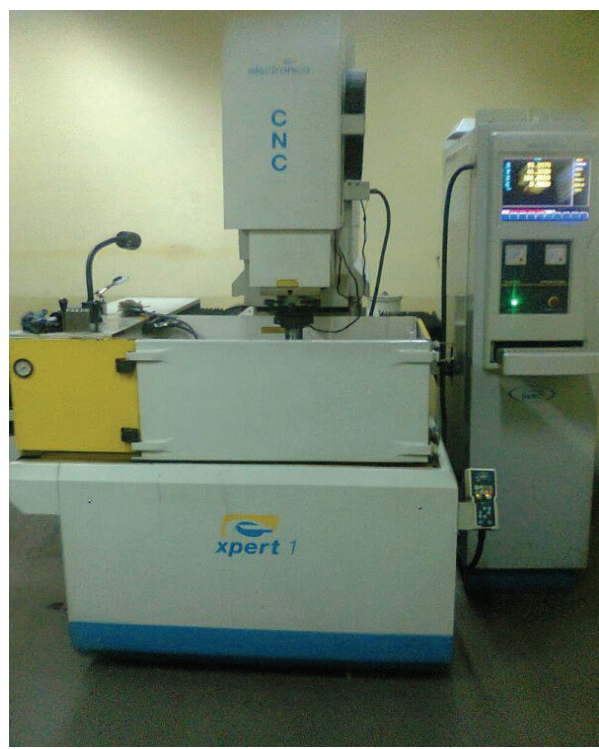

(a)

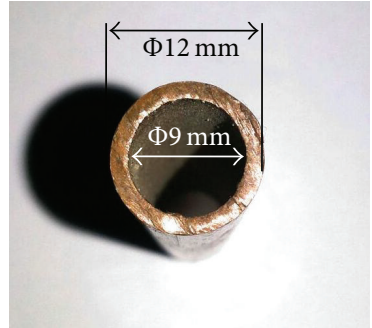

(b)

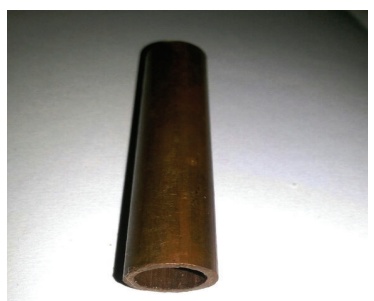

(c)

FIGURE 1: (a) CNC die sinking EDM; ((b), (c)) cross-sectional view of electrode.

TABLE 1: The composition of EN 353.

\begin{tabular}{lccccccccc}
\hline Composition & \multicolumn{1}{l}{} & & & & & & \\
\hline Contents & $\mathrm{C}$ & $\mathrm{Si}$ & $\mathrm{Mn}$ & $\mathrm{Cr}$ & $\mathrm{Mo}$ & $\mathrm{S}$ & $\mathrm{P}$ & $\mathrm{Al}$ & $\mathrm{Ni}$ \\
\hline Percentage & 0.18 & 0.22 & 0.66 & 0.89 & 0.13 & 0.033 & 0.034 & 0.026 & 1.06 \\
\hline
\end{tabular}

TABLE 2: Factors and their levels.

\begin{tabular}{|c|c|c|c|c|c|c|}
\hline \multirow{2}{*}{ Serial number } & \multirow{2}{*}{ Symbols } & \multirow{2}{*}{ Input factors } & \multicolumn{3}{|c|}{ Levels } & \multirow{2}{*}{ Units } \\
\hline & & & 1 & 2 & 3 & \\
\hline 1 & A & Pulse on time & 100 & 340 & 580 & $\mu \mathrm{s}$ \\
\hline 2 & B & Pulse off time & 4 & 16 & 28 & $\mu \mathrm{s}$ \\
\hline 3 & $\mathrm{C}$ & Peak current & 5 & 25 & 45 & $\mathrm{~A}$ \\
\hline
\end{tabular}

time. The weights of the electrodes were measured using a balance. Surface roughness measurements were carried out at the sidewall of the holes using a Brand-Mitutoyo Surftest, Model-SJ-301.

\section{Results and Discussion}

3.1. Effect of Process Parameters on Material Removal Rate. The mathematical relationship for correlating the machining rate and the considered process variables is obtained as follows:

$$
\begin{aligned}
\mathrm{MRR}= & 20.12185+0.015014 * T_{\mathrm{ON}} \\
& -0.23106 * T_{\mathrm{OFF}}-0.42890 * I_{P} \\
& +2.88377 E-005 * T_{\mathrm{ON}}^{2}+4.52138 E \\
& -003 * I_{P}^{2}-8.47222 E-004 * T_{\mathrm{ON}} * T_{\mathrm{OFF}} \\
& +0.013052 * T_{\mathrm{OFF}} * I_{P}
\end{aligned}
$$

The fit summary recommended that the quadratic model is statistically significant for analysis of MRR. The results of the quadratic model for MRR in the form of ANOVA are given in Table 4. This model was developed for $95 \%$ confidence level. The model $F$ value of 43.10 implied that the model is significant for MRR. There is only a $0.01 \%$ chance that a "model $F$ value" this large could occur due to noise.

The values of "Prob $>F$ " less than 0.05 indicate that the model terms are significant. In this case, $\mathrm{A}, \mathrm{B}, \mathrm{A}^{2}, \mathrm{C}^{2}$ $\mathrm{AB}$, and $\mathrm{BC}$ are significant model terms. The other model terms are said to be nonsignificant. The lack of fit $F$ value of 0.0801 implies that it is not significant relative to the pure

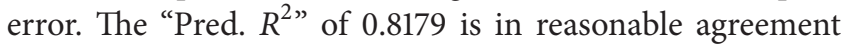

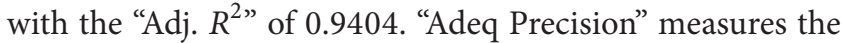
signal-to-noise ratio. A ratio greater than 4 is desirable. Your ratio of 14.843 indicates an adequate signal. Figures 2(a), 2(b), and 2(c) show the effects of different input factors (pulse on time, pulse off time, and peak current) on the response parameter MRR. Figure 2(d) shows the contour plot, while 
TABLE 3: Factors and their responses.

\begin{tabular}{|c|c|c|c|c|c|c|}
\hline \multirow{2}{*}{ Run number } & \multicolumn{3}{|c|}{ Factors } & \multicolumn{3}{|c|}{ Responses } \\
\hline & $\begin{array}{c}\text { Pulse off time } \\
T_{\text {OFF }}(\mu \mathrm{s})\end{array}$ & $\begin{array}{c}\text { Pulse on time } \\
T_{\mathrm{ON}}(\mu \mathrm{s})\end{array}$ & $\begin{array}{c}\text { Pulse current } \\
I_{P}(\mathrm{~A})\end{array}$ & $\begin{array}{c}\text { Material removal rate } \\
\operatorname{MRR}\left(\mathrm{mm}^{3} / \mathrm{min}\right)\end{array}$ & $\begin{array}{l}\text { Electrode wear rate } \\
\operatorname{EWR}\left(\mathrm{mm}^{3} / \mathrm{min}\right)\end{array}$ & $\begin{array}{c}\text { Surface roughness } \\
\operatorname{SR}(\mu \mathrm{m})\end{array}$ \\
\hline 1 & 28 & 340 & 5 & 14.6 & 4.7 & 5.39 \\
\hline 2 & 4 & 340 & 5 & 23.37 & 11.6 & 6.3 \\
\hline 3 & 16 & 340 & 25 & 18.25 & 7.4 & 7.22 \\
\hline 4 & 28 & 340 & 45 & 20.96 & 12.9 & 6.25 \\
\hline 5 & 16 & 340 & 25 & 18.85 & 5.7 & 7.45 \\
\hline 6 & 16 & 340 & 25 & 19.55 & 7.2 & 7.57 \\
\hline 7 & 4 & 580 & 25 & 28.99 & 13.8 & 10.12 \\
\hline 8 & 4 & 100 & 25 & 14.53 & 3.5 & 5.42 \\
\hline 9 & 16 & 340 & 25 & 18.86 & 5.8 & 7.23 \\
\hline 10 & 16 & 580 & 45 & 29.03 & 10.2 & 10.16 \\
\hline 11 & 16 & 100 & 5 & 14 & 3.9 & 4.28 \\
\hline 12 & 16 & 580 & 5 & 26.42 & 10.9 & 9.15 \\
\hline 13 & 16 & 100 & 45 & 16.16 & 4.1 & 5.34 \\
\hline 14 & 28 & 100 & 25 & 15.66 & 3.5 & 4.33 \\
\hline 15 & 16 & 340 & 25 & 17.8 & 5.9 & 7.43 \\
\hline 16 & 4 & 340 & 45 & 22.2 & 7.2 & 7.73 \\
\hline 17 & 28 & 580 & 25 & 24.36 & 10.4 & 9.2 \\
\hline
\end{tabular}

TABLE 4: The analysis of variance for main and interaction effects of parameters on MRR.

\begin{tabular}{lccccccc}
\hline Source & SS & DOF & MS & $F$ value & Prob $>F$ & At 95\% CI & \% contribution \\
\hline Model & 364.25 & 6 & 60.71 & 43.10 & $<0.0001$ & Significant \\
A & 293.43 & 1 & 293.43 & 208.33 & $<0.0001$ & Significant \\
$\mathrm{B}$ & 22.82 & 1 & 22.82 & 16.20 & 0.0024 & Significant \\
$\mathrm{C}$ & 12.40 & 1 & 12.40 & 8.80 & 0.0141 & Significant & \\
$\mathrm{A}^{2}$ & 13.14 & 1 & 13.14 & 9.33 & 0.0122 & Significant \\
$\mathrm{AB}$ & 8.29 & 1 & 8.29 & 5.89 & 0.0356 & Significant & Significant \\
$\mathrm{BC}$ & 14.18 & 1 & 14.18 & 10.06 & 0.0099 & Nonsignificant \\
Lack of fit & 12.31 & 6 & 2.05 & 4.62 & 0.0801 & & \\
$R^{2}$ & 0.9628 & & & & & & \\
Adjusted $R^{2}$ & 0.9404 & & & & & & \\
Predicted $R^{2}$ & 0.8179 & & & & & & \\
\hline
\end{tabular}

CI: confidence interval; DOF: degrees of freedom; MS: mean sum of squares; SS: sum of squares.

Figures 2(e) and 2(f) show three-dimensional interaction response surfaces for MRR in relation to the input parameters of peak current and pulse off time. It can be seen from the figure that MRR increases with increase in peak current. Maximum MRR is obtained at high peak current $45 \mathrm{~A}$ and pulse on time at $580 \mu \mathrm{s}$. This can be explained on the basis of increase in the rate of discharge energy, as high concentration of discharge energy in the spark gap leads to rapid melting and vaporization of metal, which leads to rises in the MRR. It was observed from the plots that MRR increases (from 14 to $29.03 \mathrm{~mm}^{3} / \mathrm{min}$ ) with increase in peak current and pulse on time. Figures 2(g), 2(h), and 2(i) display the normal probability plot of residuals and residual versus predicted plots for MRR. It was observed that the residuals generally fall on a straight line implying that the errors are normally distributed.
3.2. Effect on Electrode Wear Rate. The mathematical relationship for correlating the electrode wear rate and the considered process variables is obtained as follows:

\section{Electrode Wear Rate}

$$
\begin{aligned}
= & +1.51042-7.34375 E-003 * T_{\mathrm{ON}} \\
& +0.16875 * T_{\mathrm{OFF}}+0.028125 * I_{P}+7.13976 E \\
& -005 * T_{\mathrm{ON}}^{2}-2.17014 E-003 * T_{\mathrm{OFF}}^{2} \\
& -1.46875 E-003 * I_{P}^{2}-8.15972 E \\
& -004 * T_{\mathrm{ON}} * T_{\mathrm{OFF}}-9.89583 E \\
& -005 * T_{\mathrm{ON}} * I_{P}+2.70833 E-003 * T_{\mathrm{OFF}} * I_{P}
\end{aligned}
$$




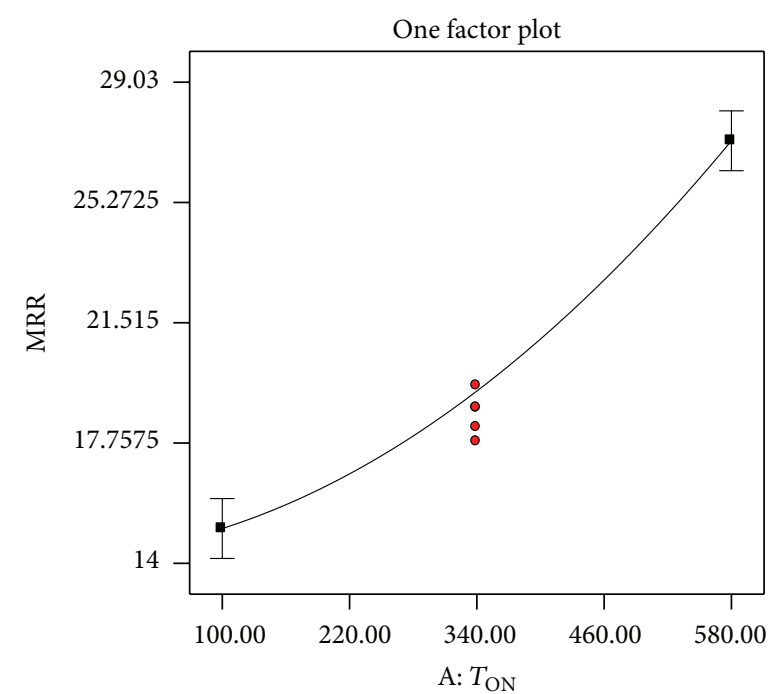

(a)

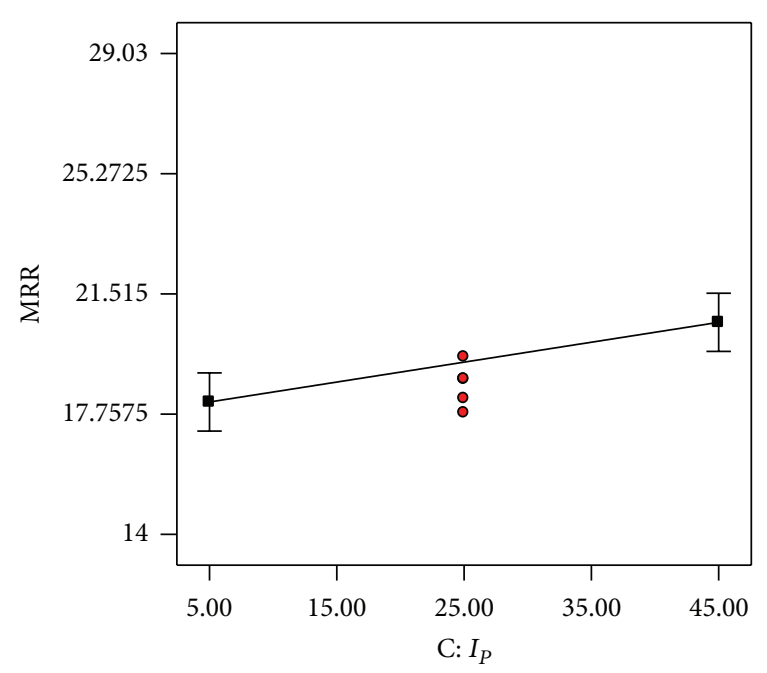

(c)

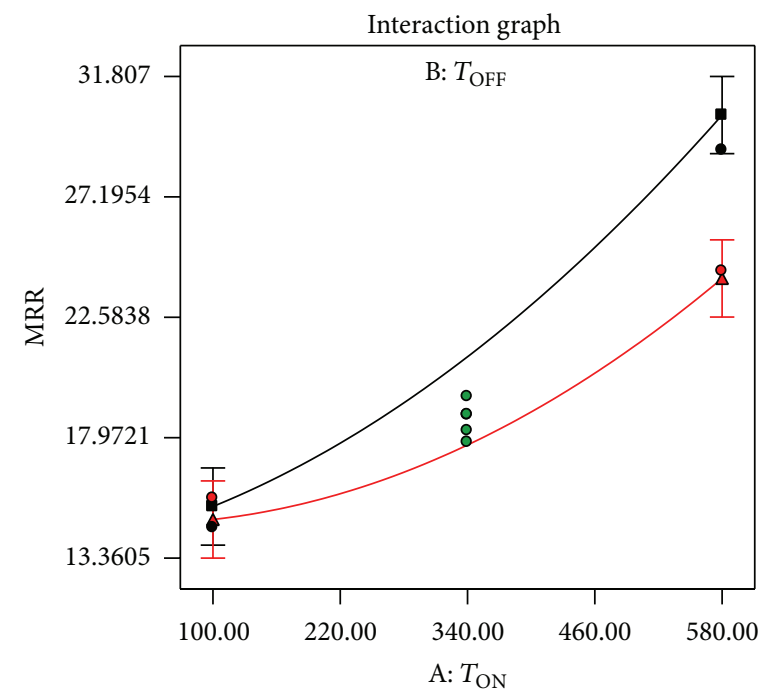

(e)

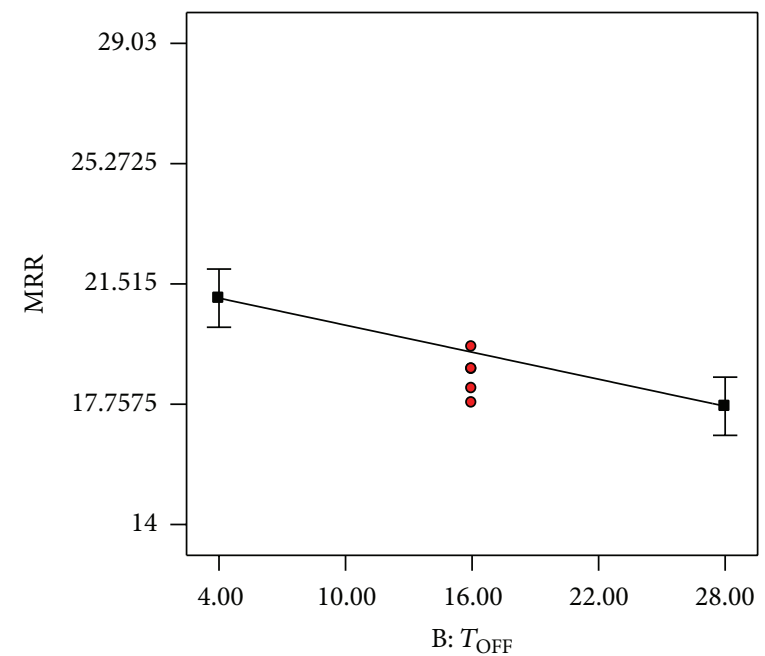

(b)

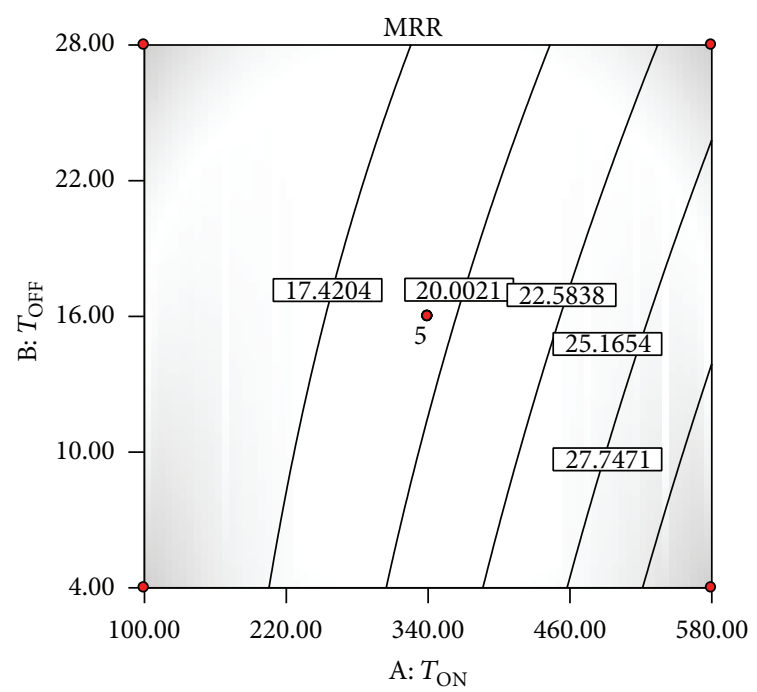

(d)

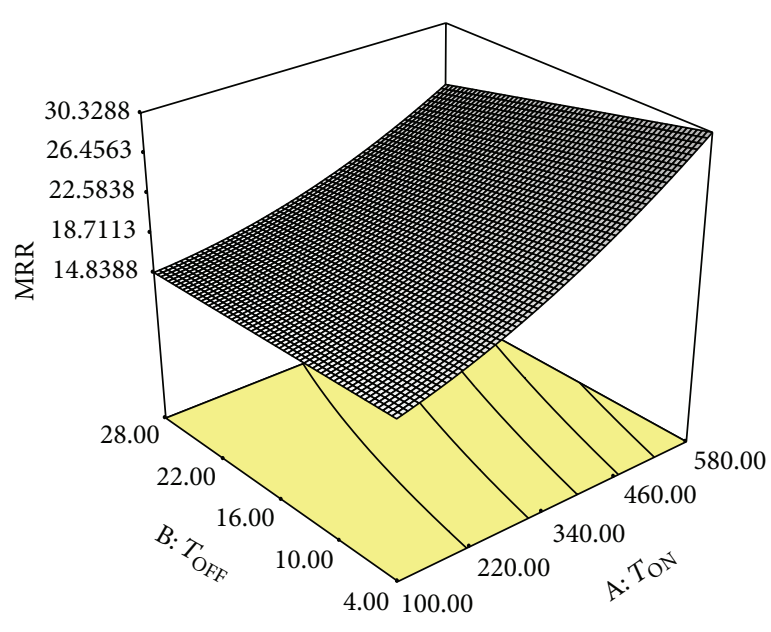

(f)

Figure 2: Continued. 


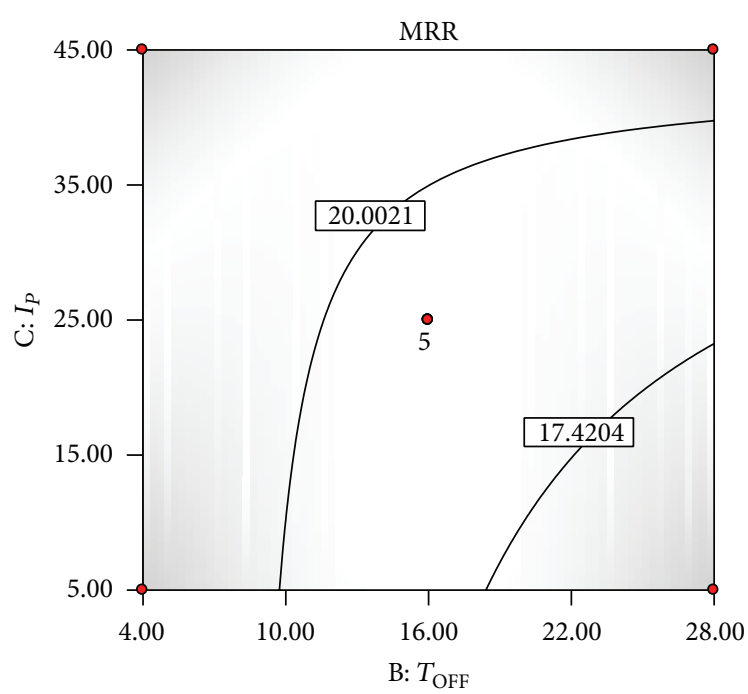

(g)

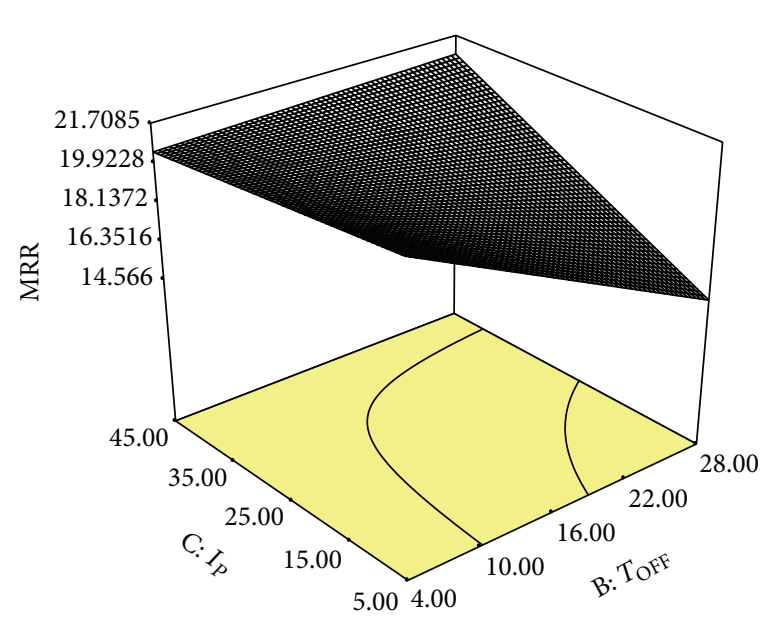

(i)

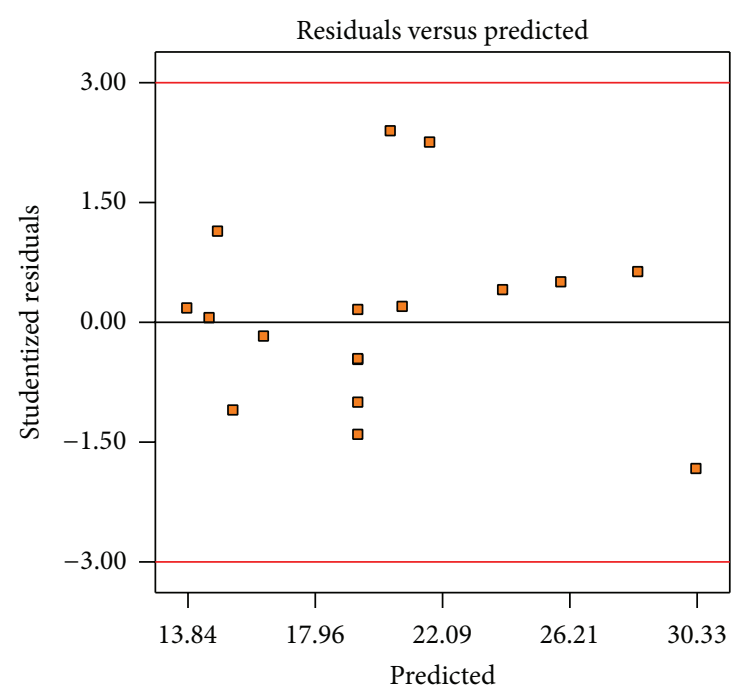

(k)

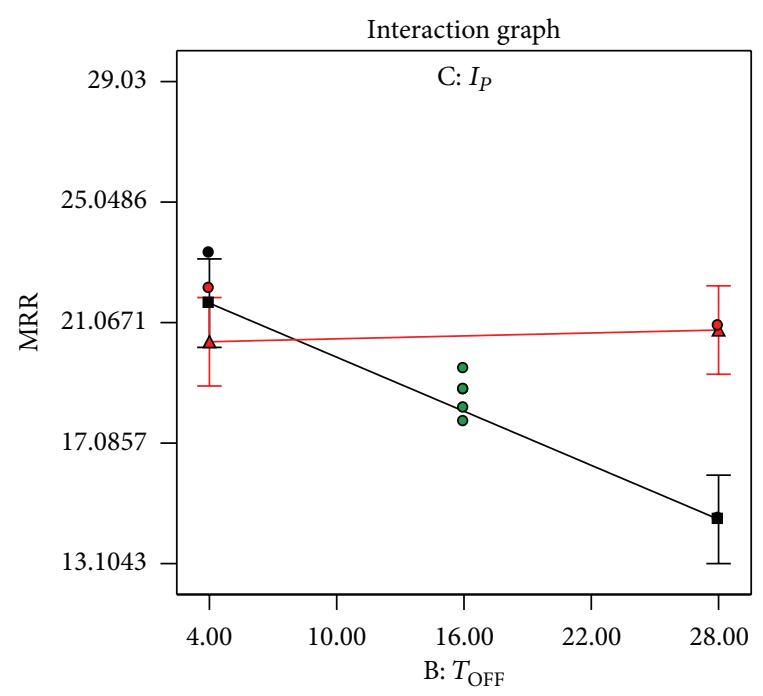

(h)

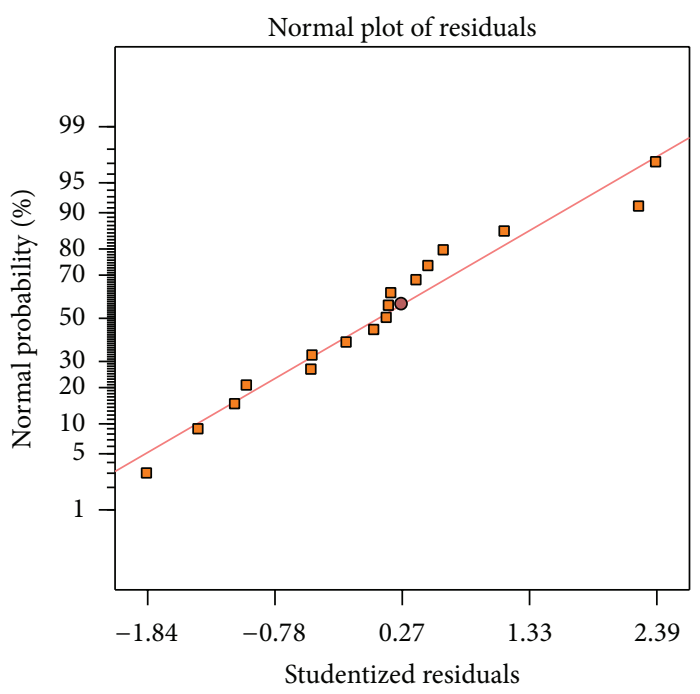

(j)

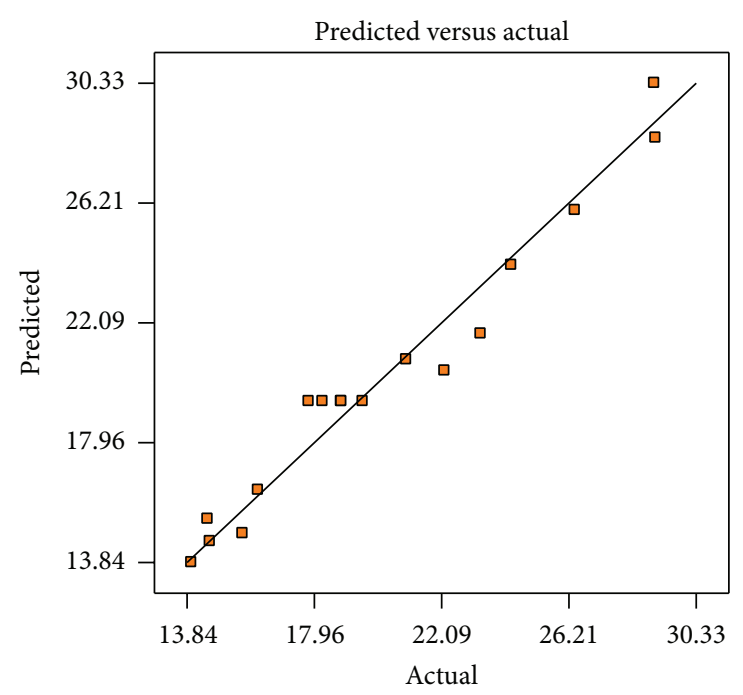

(l)

Figure 2: Response surface plot for MRR: (a) $T_{\mathrm{ON}}$ factor plot, (b) $T_{\mathrm{OFF}}$ factor plot, (c) $I_{P}$ factor plot, (d) contour plot between $T_{\mathrm{ON}}$ and $T_{\mathrm{OFF}}$, ((e) and (f)) interactions plot between $T_{\mathrm{ON}}$ and $T_{\mathrm{OFF}}$, (g) contour plot between $T_{\mathrm{OFF}}$ and $I_{P}$, ((h) and (i)) interactions plot between $T_{\mathrm{OFF}}$ and $I_{P}$, (j) normal plot of residuals, (k) residuals versus predicted values, and (l) predicted versus actual values. 
TABLE 5: The analysis of variance for main and interaction effects of parameters on EWR.

\begin{tabular}{|c|c|c|c|c|c|c|c|}
\hline Source & SS & DOF & MS & $F$ value & Prob $>F$ & At $95 \% \mathrm{CI}$ & $\%$ contribution \\
\hline Model & 170.14 & 5 & 34.03 & 23.50 & $<0.0001$ & Significant & \\
\hline A & 114.76 & 1 & 114.76 & 79.24 & $<0.0001$ & Significant & 70.39 \\
\hline B & 2.64 & 1 & 2.64 & 1.83 & 0.2037 & & 3.25 \\
\hline $\mathrm{C}$ & 1.36 & 1 & 1.36 & 0.94 & 0.3531 & & 0.94 \\
\hline $\mathrm{B}^{2}$ & 11.69 & 1 & 11.69 & 8.07 & 0.0161 & & 0.09 \\
\hline $\mathrm{BC}$ & 39.69 & 1 & 39.69 & 27.40 & 0.0003 & Significant & 0.39 \\
\hline Lack of fit & 13.19 & 7 & 1.88 & 2.75 & 0.1725 & Nonsignificant & \\
\hline$R^{2}$ & 0.9144 & & & & & & \\
\hline Adjusted $R^{2}$ & 0.8755 & & & & & & \\
\hline Predicted $R^{2}$ & 0.7301 & & & & & & \\
\hline
\end{tabular}

CI: confidence interval; DOF: degrees of freedom; MS: mean sum of squares; SS: sum of squares.

TABLE 6: The analysis of variance for main and interaction effects of parameters on SR.

\begin{tabular}{lccccccc}
\hline Source & SS & DOF & MS & $F$ value & Prob $>F$ & At 95\% CI & \% contribution \\
\hline Model & 53.68 & 7 & 7.67 & 550.62 & $<0.0001$ & Significant \\
$\mathrm{A}$ & 46.37 & 1 & 46.37 & 3329.21 & $<0.0001$ & Significant \\
$\mathrm{B}$ & 2.42 & 1 & 2.42 & 173.75 & $<0.0001$ & Significant \\
$\mathrm{C}$ & 2.38 & 1 & 2.38 & 170.61 & $<0.0001$ & Significant \\
$\mathrm{A}^{2}$ & 0.52 & 1 & 0.52 & 37.30 & 0.0002 & Significant \\
$\mathrm{B}^{2}$ & 0.91 & 1 & 0.91 & 65.02 & $<0.0001$ & Significant \\
$\mathrm{C}^{2}$ & 1.05 & 1 & 1.05 & 75.20 & $<0.0001$ & Significant \\
$\mathrm{BC}$ & 0.081 & 1 & 0.081 & 5.83 & 0.0389 & Significant \\
Lack of fit & 0.034 & 5 & $6.75 E-003$ & 0.29 & 0.8937 & Nonsignificant \\
$R^{2}$ & 0.9977 & & & & & & \\
Adjusted $R^{2}$ & 0.9959 & & & & & & \\
Predicted $R^{2}$ & 0.9921 & & & & &
\end{tabular}

CI: confidence interval; DOF: degrees of freedom; MS: mean sum of squares; SS: sum of squares.

The fit summary recommended that the quadratic model is statistically significant for analysis of EWR. The results of the quadratic model for EWR in the form of ANOVA are given in Table 5. This model was developed for 95\% confidence level. The model $F$ value of 23.50 implies that the model is significant. There is only a $0.02 \%$ chance that "model $F$ value" this large could occur due to noise. Values of "Prob > F" less than 0.05 indicate that model terms are significant. In this case, $\mathrm{A}, \mathrm{B}, \mathrm{A}^{2}$, and $\mathrm{AB}$ are significant model terms. The "lack of fit $F$ value" of 0.1725 implies the lack of fit is not significant relative to the pure error. The

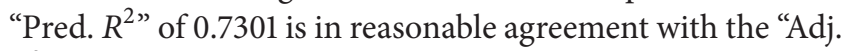

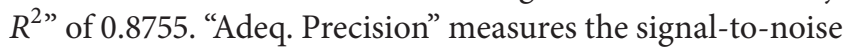
ratio. A ratio greater than 4 is desirable. The ratio of 16.222 indicates an adequate signal. This ratio of 16.222 indicates an adequate signal. Figures 3(a), 3(b), and 3(c) show the effects of different input factors (pulse on time, pulse off time, and peak current) on the response parameter EWR. Figure 3(d) shows the contour plot, while Figures 3(e) and 3(f) show three-dimensional interaction response surfaces for EWR in relation to the input parameters of peak current and pulse off time. From the contour plot and response surface, it was observed that minimum EWR $3.5 \mathrm{~mm}^{3} / \mathrm{min}$ with the low value of peak current at $4 \mathrm{~A}$ and pulse off time at $4 \mu \mathrm{s}$. In addition to this, Figures $2(\mathrm{~g}), 2(\mathrm{~h})$, and $2(\mathrm{i})$ show that the normal plot of residuals data is normally distributed.

3.3. Effect of Process Parameters on Surface Roughness. The mathematical relationship for correlating the surface roughness and the considered process variables is obtained as follows:

$$
\begin{aligned}
& \text { Surface Roughness } \\
& \begin{aligned}
= & +2.88516+5.88455 E-003 * T_{\mathrm{ON}} \\
& +0.072066 * T_{\mathrm{OFF}}+0.099094 * I_{P} \\
& +6.09809 E-006 * T_{\mathrm{ON}}^{2}-3.22049 E \\
& -003 * T_{\mathrm{OFF}}^{2}-1.24687 E-003 * I_{P}^{2} \\
& -5.93750 E-004 * T_{\mathrm{OFF}} * I_{P} .
\end{aligned}
\end{aligned}
$$

Based on ANOVA as shown in Table 6 , the model $F$ value of 550.62 implies that the model is significant. There is only 


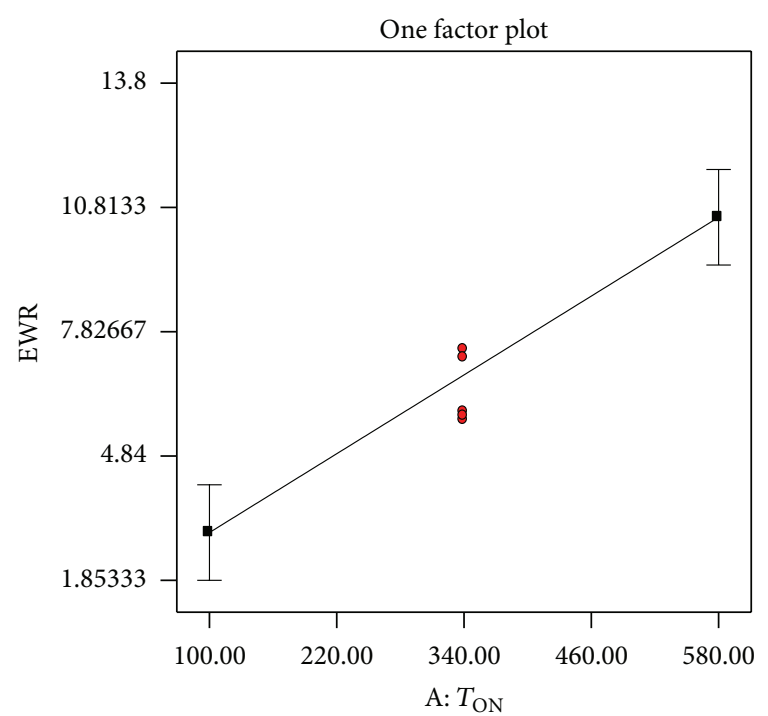

(a)

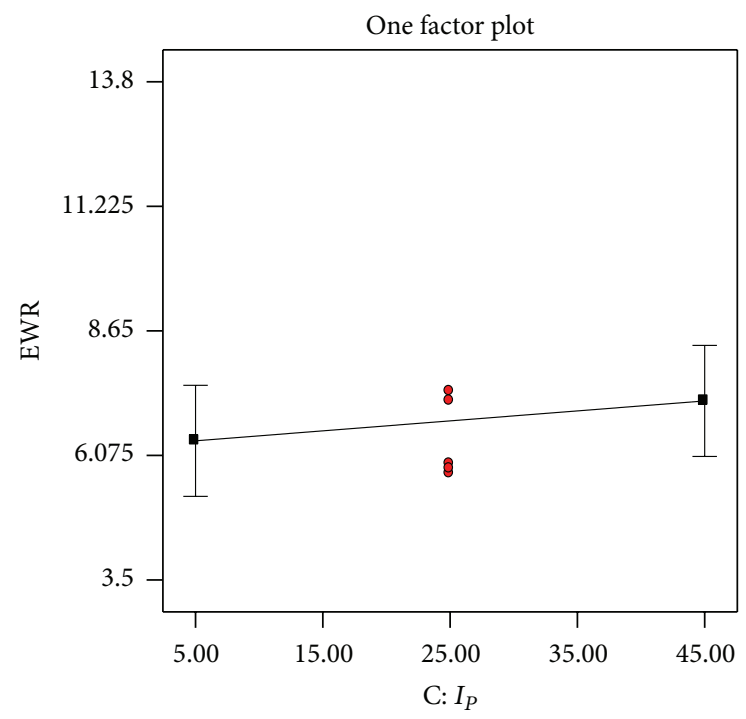

(c)

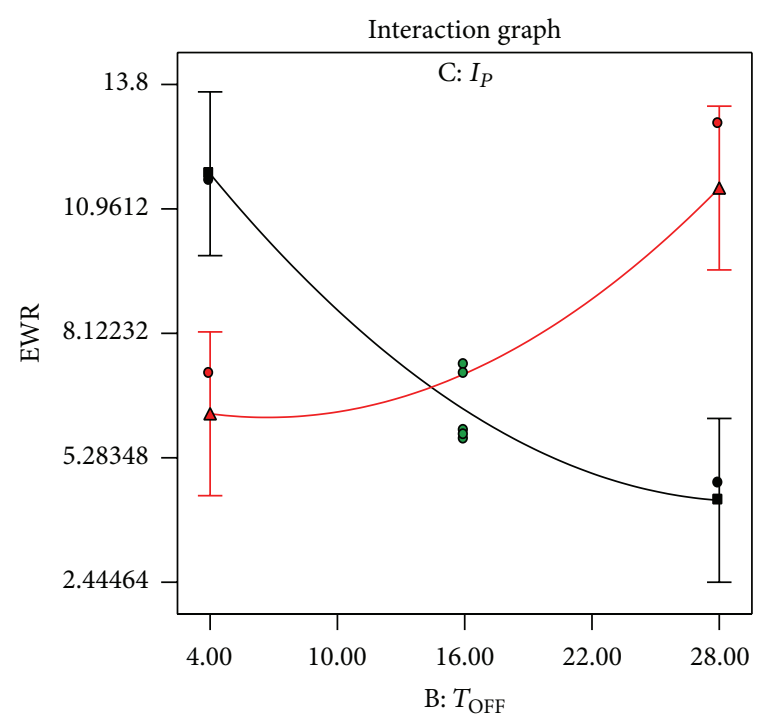

(e)

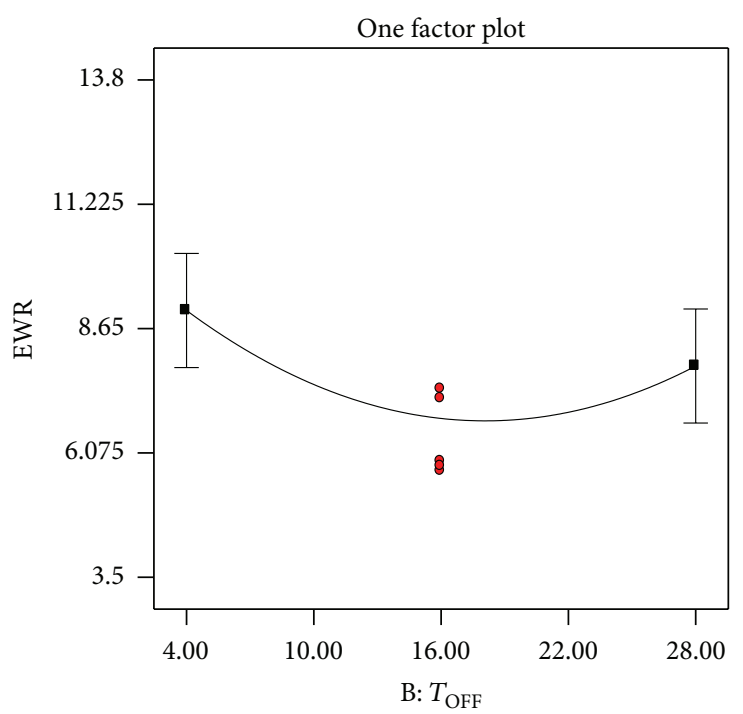

(b)

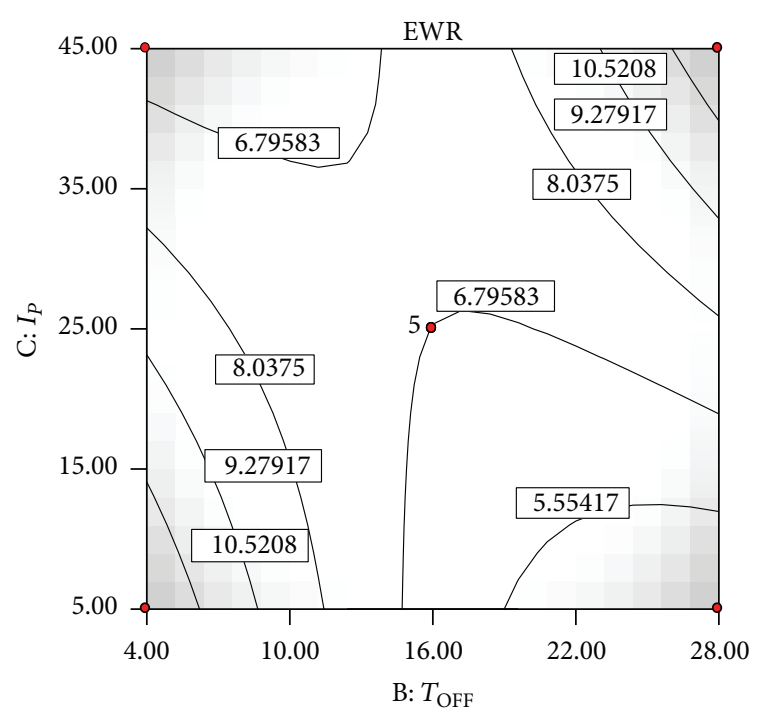

(d)

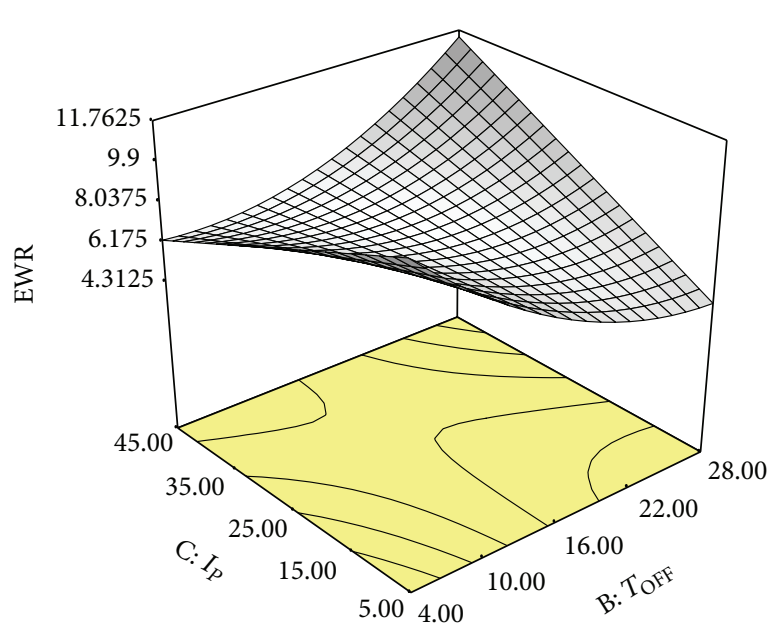

(f)

Figure 3: Continued. 


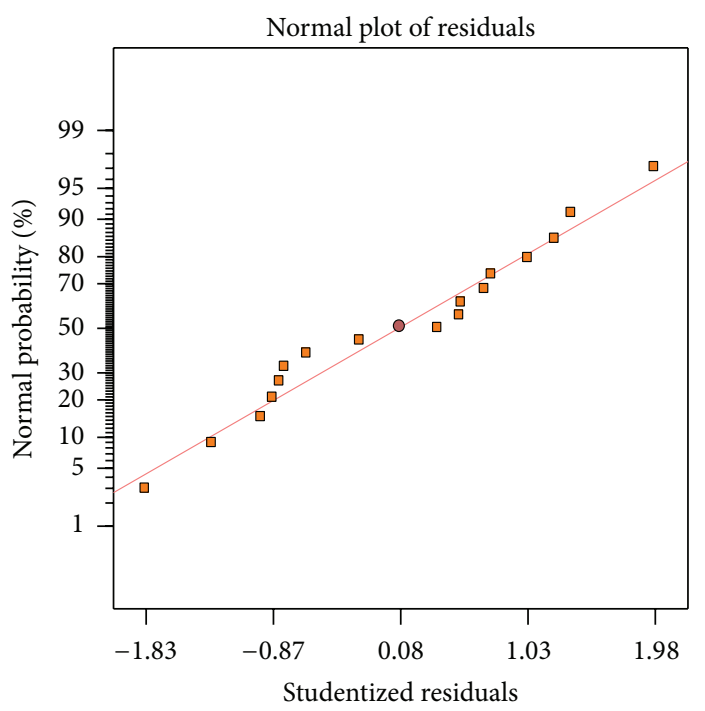

(g)

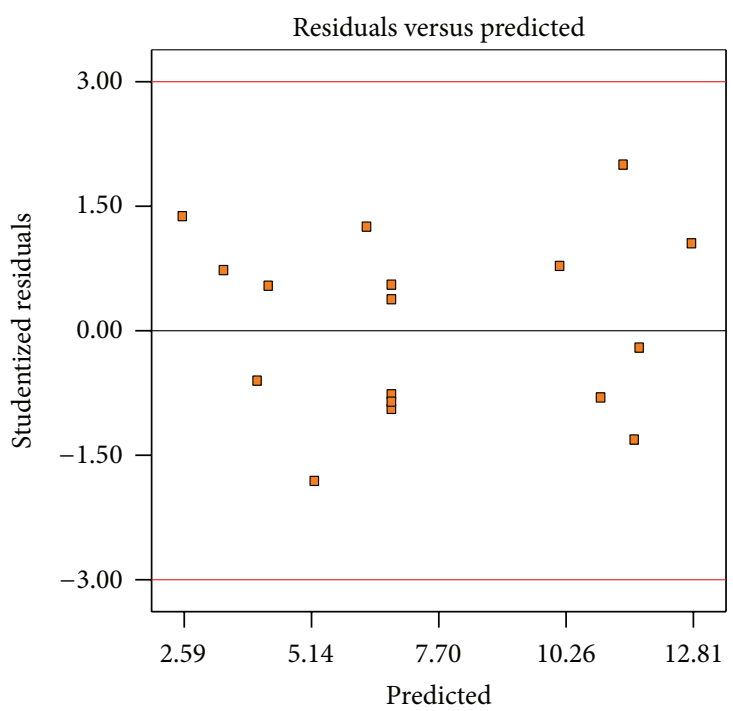

(h)

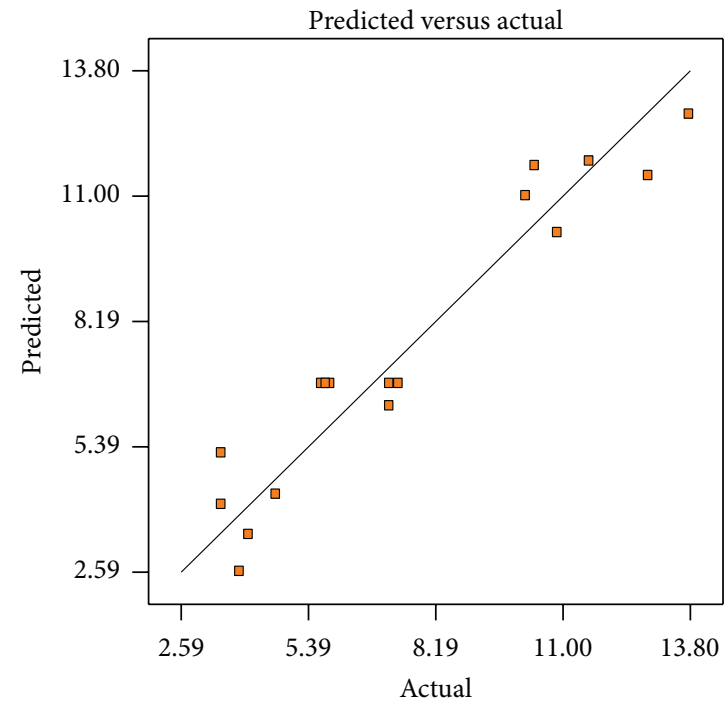

(i)

Figure 3: Response surface plot for EWR: (a) $T_{\mathrm{ON}}$ factor plot, (b) $T_{\mathrm{OFF}}$ factor plot, (c) $I_{P}$ factor plot, (d) contour plot between $T_{\mathrm{OFF}}$ and $I_{P}$, ((e) and (f)) interactions plot between $T_{\mathrm{OFF}}$ and $I_{p}$, (g) normal plot of residuals, (h) residuals versus predicted values, and (i) predicted versus actual values.

a $0.01 \%$ chance that a "model $F$ value" this large could occur due to noise. Values of "Prob $>F$ " less than 0.0500 indicate model terms are significant. In this case $A, B, C, A^{2}, B^{2}, C^{2}$, and $\mathrm{BC}$ are significant model terms. The "lack of fit $F$ value" of 0.8937 implies that the lack of fit is not significant relative to the pure error. There is a $89.37 \%$ chance that a "lack of fit $F$ value" this large could occur due to noise. The "Pred. $R^{2 \text { " of }}$

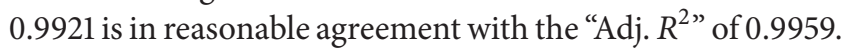
"Adeq Precision" measures the signal-to-noise ratio. A ratio greater than 4 is desirable. Your ratio of 73.433 indicates an adequate signal. This model can be used to navigate around the design space. Figure 4(a) shows the contour plot, while
Figures 4(b) and 4(c) show three-dimensional interaction response surfaces for SR in relation to the input parameters of peak current and pulse off time.

From the contour plot and response surface, it was observed that minimum SR $4.29 \mu \mathrm{m}$ with the value of peak current at $16 \mathrm{~A}$ and pulse off time at $100 \mu \mathrm{s}$. In addition to this, Figures 4(d), 4(e), and 4(f) show that the normal plot of residuals data is normally distributed and all the experimental results are in the region very near to the predicted values, and, hence, the developed model can be effectively used to predict the surface roughness in EDM of EN 353. At higher peak current, the discharge energy per pulse increases, which 


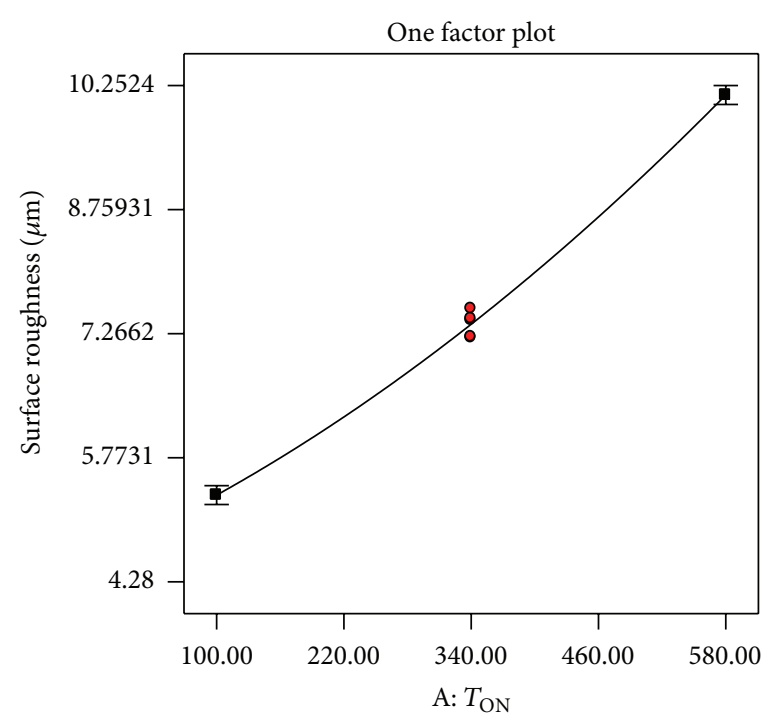

(a)

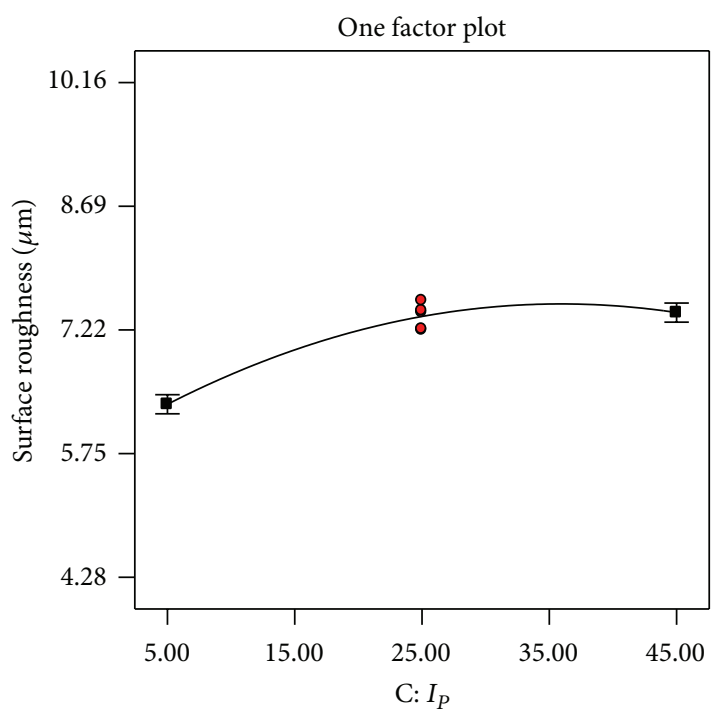

(c)

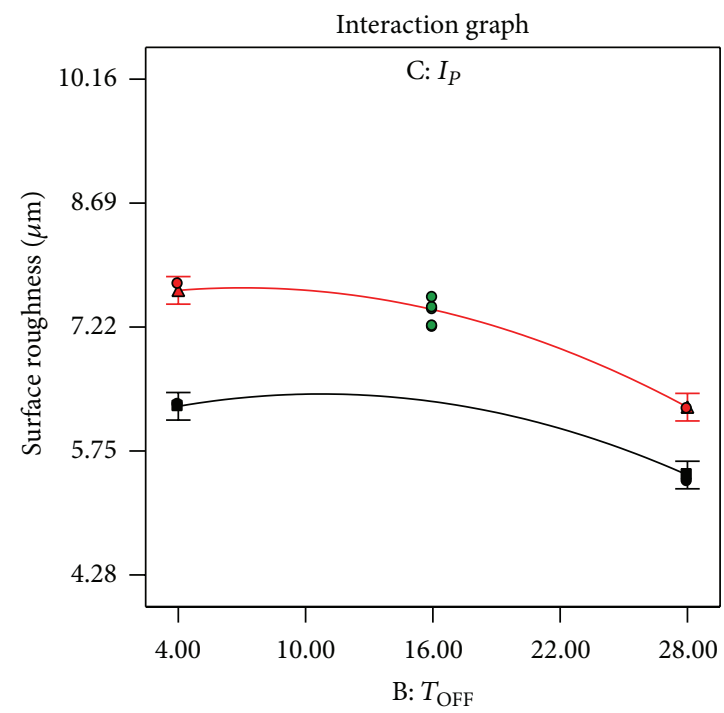

(e)

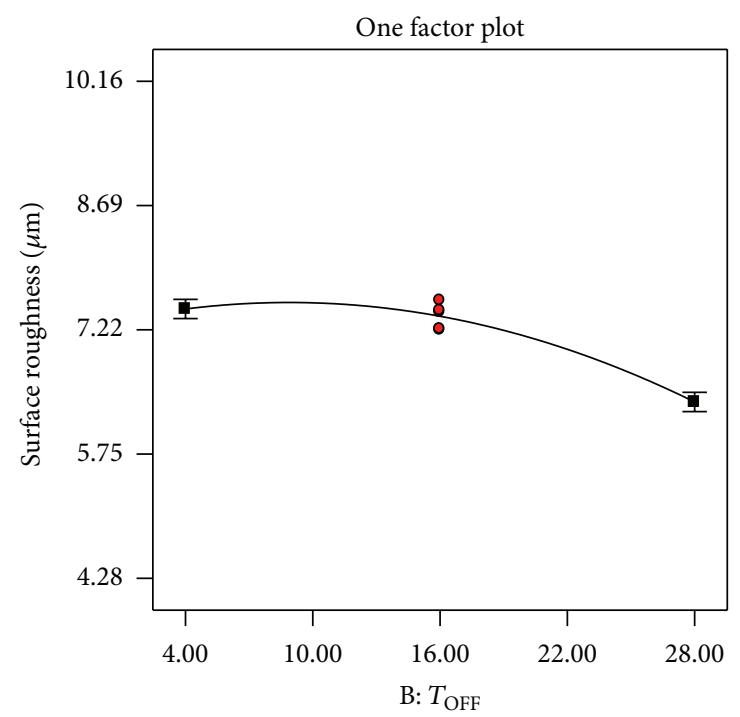

(b)

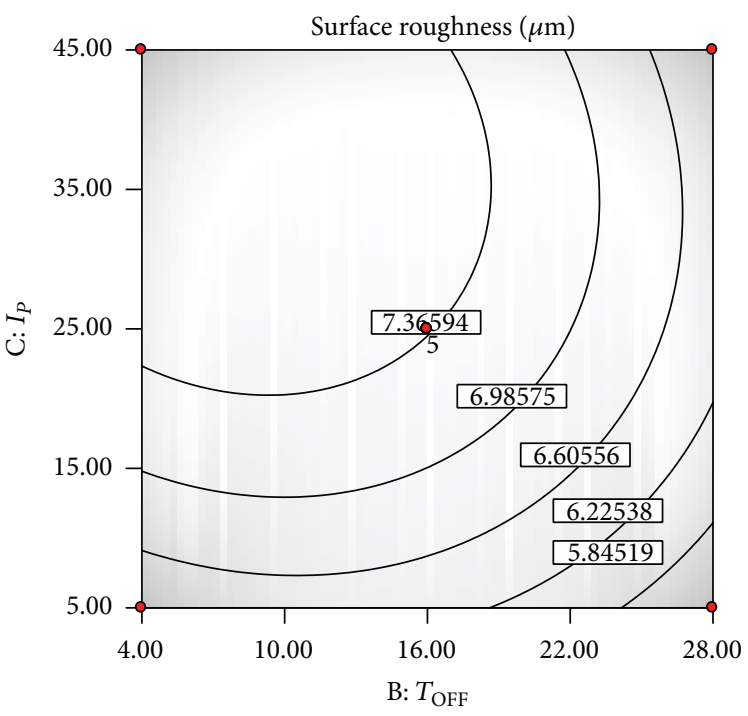

(d)

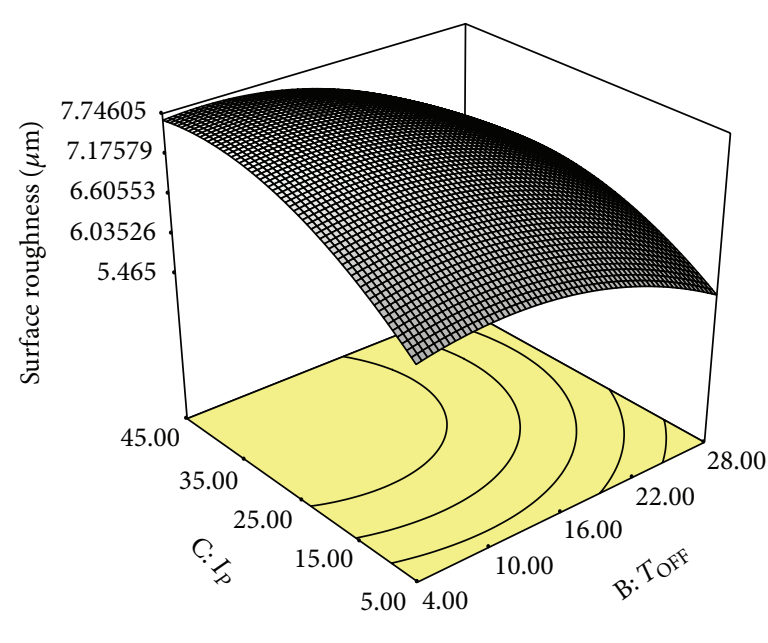

(f)

Figure 4: Continued. 


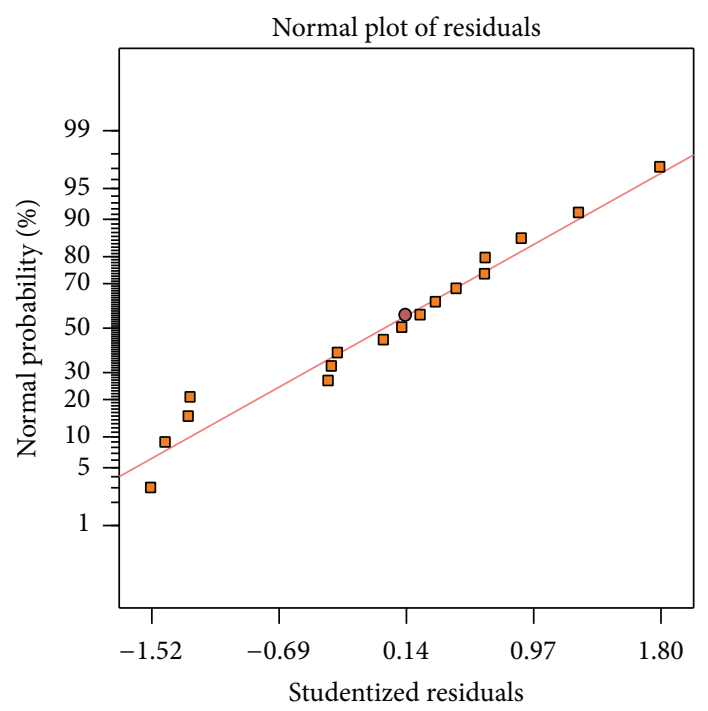

(g)

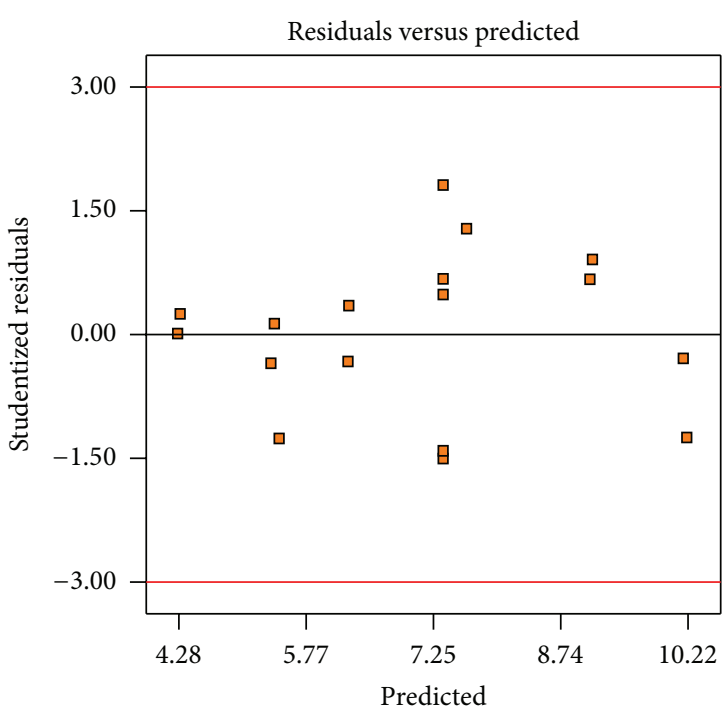

(h)

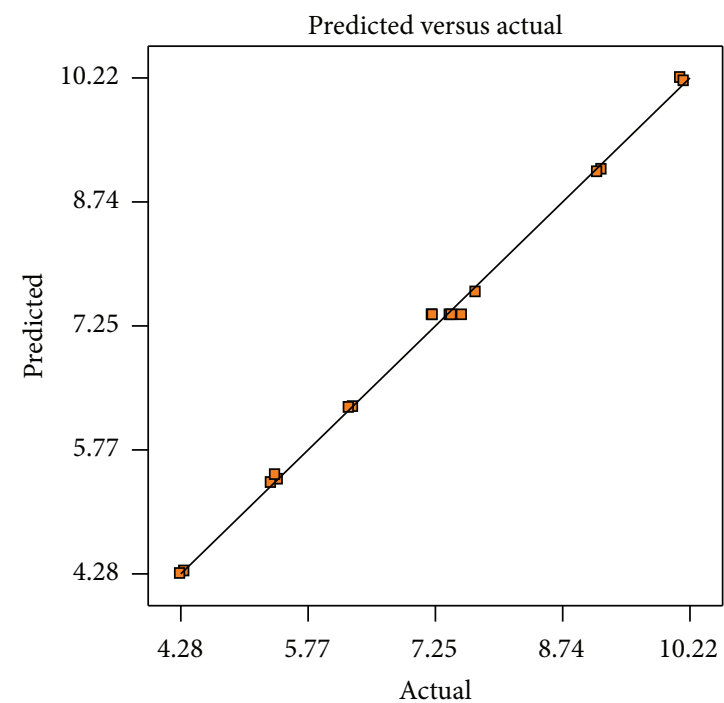

(i)

Figure 4: Response surface plot for SR: (a) $T_{\mathrm{ON}}$ factor plot, (b) $T_{\mathrm{OFF}}$ factor plot, (c) $I_{P}$ factor plot, (d) contour plot between $T_{\mathrm{OFF}}$ and $I_{P}$, ((e) and (f)) interactions plot between $T_{\mathrm{OFF}}$ and $I_{P}$, (g) normal plot of residuals, (h) residuals versus predicted values, and (i) predicted versus actual values.

produces the deeper and wider overlapping craters, globules of debris, and microcracks on the machined samples as seen in SEM micrographs (Figure 5).

3.4. Microstructure Analysis. During EDM process, the discharged energy produces very high temperatures at the point of the spark, causing a minute part of the sample to melt and vaporizes. With each discharge, a crater was formed on the machined surface. It was observed from Figure 5. SEM micrographs that, EDM surface produces irregular topography and defects included globules of debris, spherical particles, varying size craters, and microcracks [28]. The surface topography was altered owing to significant electrical parameters such as pulse on time, pulse off time, and peak current. The pulse on time and peak current are the most significant parameters that lead to deterioration of the surface texture. When pulse on time was increased, the surface texture of the machined surface is composed of varying sizes of deep craters. These deep and overlapping craters were formed owing to successive electrical discharge, intense heat, and local melting or vaporization of work material. Some of the molten materials produced by the discharge was carried away by the kerosene. The remaining molten material resolidifies to form lumps of debris. Under shorter pulse on time, electrical sparks generate smaller craters on the work surface. The high pulsed current caused frequent cracking 


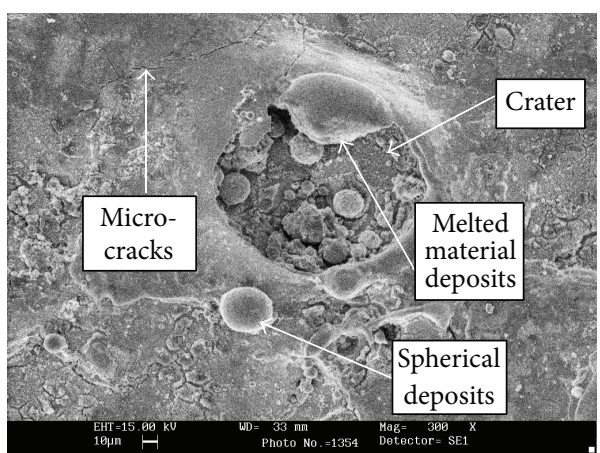

(a)

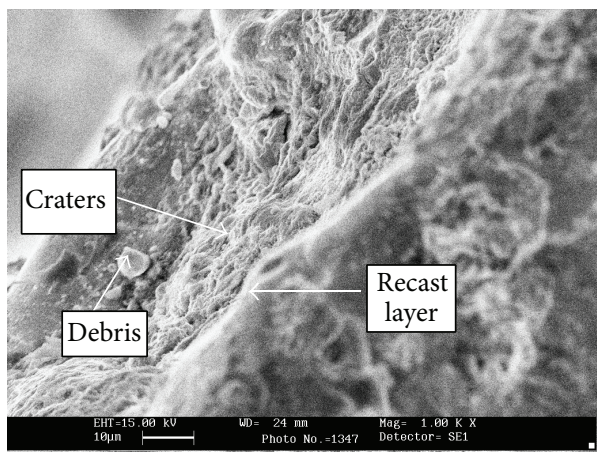

(c)

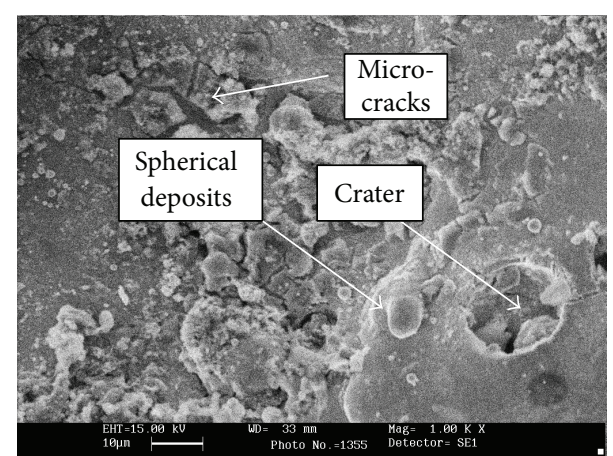

(b)

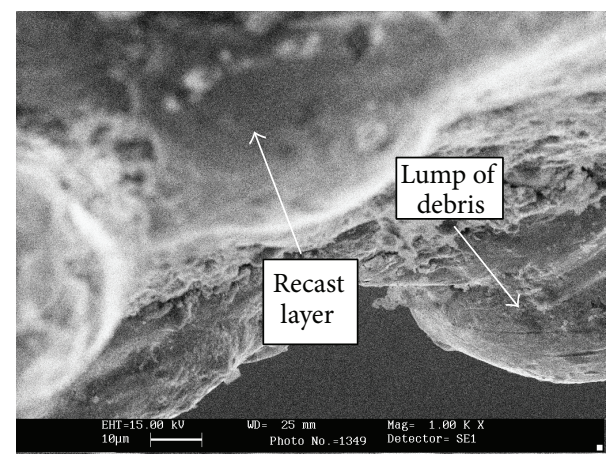

(d)

FIgURE 5: SEM micrograph: (a) Experiment number 3, at $T_{\mathrm{ON}}=340 \mu \mathrm{s}, T_{\mathrm{OFF}}=16 \mu \mathrm{s}$, and $I_{P}=25 \mathrm{~A}$; (b) experiment number 17 , at $T_{\mathrm{ON}}=$ $580 \mu \mathrm{s}, T_{\mathrm{OFF}}=28 \mu \mathrm{s}$, and $I_{P}=25 \mathrm{~A}$; (c) experiment number 13, at $T_{\mathrm{ON}}=100 \mu \mathrm{s}, T_{\mathrm{OFF}}=4 \mu \mathrm{s}$, and $I_{P}=45 \mathrm{~A}$; and (d) experiment number 12 , at $T_{\mathrm{ON}}=580 \mu \mathrm{s}, T_{\mathrm{OFF}}=16 \mu \mathrm{s}$, and $I_{P}=5 \mathrm{~A}$.

of dielectric fluid, causing more melt expulsions and larger tensile stresses. These effects resulted in poor surface finish. At higher peak current, the impact of discharge energy on the surface of workpiece becomes greater, and, thus, the resulting erosion leads to the increase in deterioration of surface roughness. The recast layer is the outer region of the heat affected zone and consists of superimposed strata derived from melted and resolidified workpiece material as seen in Figure 5. This layer is caused by the material that was melted during the discharge and then when the discharge current breakdown occurred, a part of the material has resolidified in the crater and surroundings and the rest was flushed away by the dielectric [6]. The structure of the recast layer that is formed on steels consists mainly of iron carbides in acicular or globular form, distributed within an austenite matrix, which are independent of the composition of the base material and of the type of the electrode, that is, copper or graphite. The increase in carbon content in the recast layer is intrinsically related to the pyrolysis products that follows the cracking of the dielectric and is very confined to the melted and resolidified work piece material forming the iron carbides. Due to the very high cooling gradient from the surface into the matrix material, the iron carbides are normally oriented perpendicularly to the surface.

Figure 6 reveals the existence of cracks which start on the white layer and progress in the HAZ. The fundamental cause of cracking lies in the existence of the intern stresses which are created at the time of the machining operation. The surface crack density and the depth of these cracks are directly related to the machining conditions; the more we increase the discharge energy, the more the appearance frequency of these cracks increases. These types of cracking are due to very high temperature, because cracking at high temperature is due to the phenomena of segregation to solidification, which is due to the enrichment in certain elements, as solidification progresses and the intern stresses grow. The elements which have a harmful effect on steel and which increase its tendency to cracking are silicon, nickel, sulphur, phosphorus, and carbon [14]. The segregation comes owing to the fact that the grain boundaries generally constitute preferential sites for the impurities. The heating at very high temperature, during flashing, involves the enlargement of the grain of metal which implies the migration of the grain joints; during this migration, the joints of the grains rake the impurities which are in metal, and it is possible that this causes local concentrations in impurities. The presence of these cracks is also due to the presence of the elements strongly conducting in material as copper which let penetrate the current of discharge. It results in preferential energy propagation from it through these elements which can lead to total or partial separation of certain grains.

During EDM, some particles eroding from the tool electrode stick on the machined hole surface as seen in Figures 3 (a) and 4(c), leading to formation of a rough surface with 


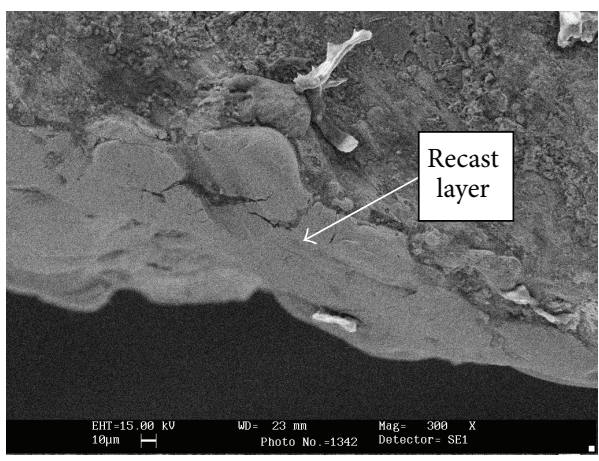

(a)

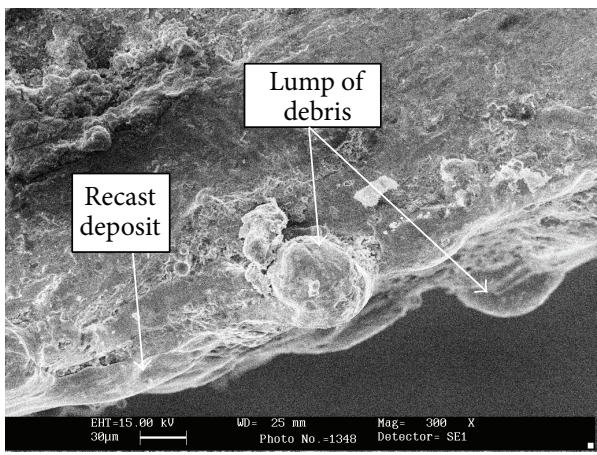

(c)

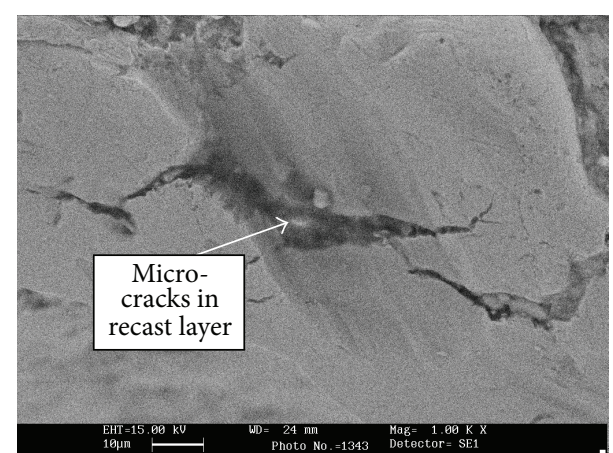

(b)

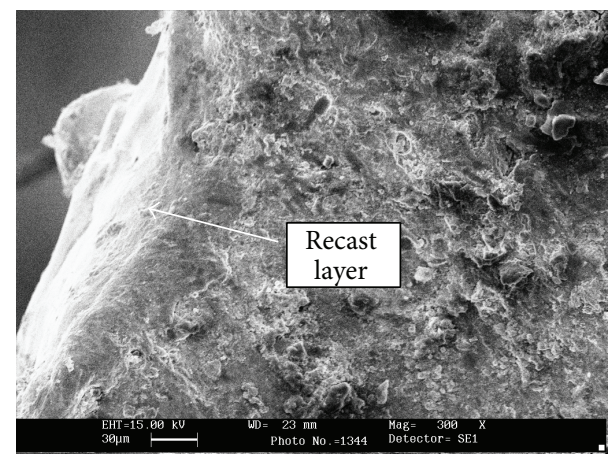

(d)

Figure 6: Recast layer: (a) experiment number 3, at $T_{\mathrm{ON}}=340 \mu \mathrm{s}, T_{\mathrm{OFF}}=16 \mu \mathrm{s}$, and $I_{P}=25 \mathrm{~A}$; (b) experiment number 10 , at $T_{\mathrm{ON}}=580 \mu \mathrm{s}$, $T_{\mathrm{OFF}}=16 \mu \mathrm{s}$, and $I_{P}=45 \mathrm{~A}$; (c) experiment number 16 , at $T_{\mathrm{ON}}=340 \mu \mathrm{s}, T_{\mathrm{OFF}}=4 \mu \mathrm{s}$, and $I_{P}=45 \mathrm{~A} ;(\mathrm{d})$ experiment number 17 , at $T_{\mathrm{ON}}=$ $580 \mu \mathrm{s}, T_{\mathrm{OFF}}=28 \mu \mathrm{s}$, and $I_{P}=25 \mathrm{~A}$.

irregularities. Such damages are even more intensively dispersed on the corresponding surfaces of blind holes [7]. This is due to the reason that the particles eroding from the surface being machined cannot be flushed away sufficiently. Thereby, even rougher surfaces are obtained during the production of blind holes upon solidification of debris and melted drops on the surface. It should be noted that these damages occurring during EDM process can be minimized by establishing the optimized process parameters to achieve desirable surface quality.

3.5. Multiresponse Optimization Based on Desirability. The desirability function can be used to combine multiple responses into one response called the "desirability function" by choice of value from 0 (one or more product characteristics are unacceptable) to 1 (all product characteristics are on target). The method is attractive because it is intuitive and simple [18]. The inputs are mean response estimates, target value, and upper and lower acceptability bounds. The individual desirability is combined using the geometric mean. The desirability of a product characteristic value depends on the lower and upper ranges of product specification. Improper selection of ranges can result in a very different "optimum." The basic idea of the desirability function approach is to transform a multiple response problem into a single response problem by means of mathematical transformations. The desirability function involves transformation of each estimated response variable $\hat{y}$ to a desirability value $d i$, where $0 \leq d i \leq 1$.

The value of $d i$ increases as the "desirability" of the corresponding response increases. The procedure followed in this work for simultaneous optimization of the three responses is a modification of the method developed by Derringer and Suich and El-Taweel.

Step 1. Calculate the individual desirability $(d i)$ for each response $(\widehat{y})$.

Step 2. Combine individual desirabilities to obtain composite desirability (DG) for given weights of MRR, EWR, and surface roughness. Composite desirability is the weighted geometric mean of individual desirability for the given responses.

Step 3. Maximize the composite desirability and identify the optimal parameter combinations:

$$
d i= \begin{cases}0 & \hat{y}<A i \\ \left(\hat{y}-\frac{A i}{t i}-A i\right)^{w} & A i \leq \hat{y} \leq t i \\ 1 & \hat{y}>t i .\end{cases}
$$


TABLE 7: Constraints for desirability analysis.

\begin{tabular}{lcccccc}
\hline Parameter & Goal & Lower limit & Upper limit & Lower weight & Upper weight & Importance \\
\hline$T_{\mathrm{ON}}$ & Is in range & 100 & 580 & 1 & 1 & 1 \\
$T_{\mathrm{OFF}}$ & Is in range & 4 & 16 & 1 & 1 & 3 \\
$I_{P}$ & Is in range & 5 & 29.03 & 1 & 1 & 3 \\
MRR & Maximum & 14 & 12.9 & 1 & 1 & 3 \\
EWR & Minimum & 3.5 & 10.16 & 1 & 1 & 3 \\
SR & Minimum & 5.39 & & & 1 & 3 \\
\hline
\end{tabular}

If the target $(t i)$ is to minimize a response, the individual desirability (di) is calculated as

$$
d i= \begin{cases}1 & \hat{y}<t i \\ \left(B i-\frac{\widehat{y}}{B i}-t i\right)^{w} & t i \leq \hat{y} \leq B i \\ 0 & \widehat{y}>B i,\end{cases}
$$

where $A i$ is the lower limit value of response $\hat{y}$ and $B i$ is the upper limit value of response $\widehat{y}$.

If the object for the response is a target value, then individual desirability $(\mathrm{di})$ is calculated as

$$
\begin{aligned}
& d i=\left[\frac{(\hat{y}-A i)}{(t i-A i)}\right]^{w} \quad A i \leq \hat{y} \leq t i \\
& d i=\left[\frac{(B i-\widehat{y})}{(B i-t i)}\right]^{w} \quad t i \leq \hat{y} \leq B i \\
& d i=0 \quad \text { if } \hat{y}<A i \\
& d i=0 \quad \text { if } \hat{y}>B i .
\end{aligned}
$$

If the importance is same for each response, the composite desirability (DG), the geometric mean of all desirability functions, is given by

$$
\mathrm{DG}=\left(d_{1} \times d_{2} \times \cdots \times d_{n}^{w_{n}}\right)^{1 / n}=\left(\prod d i\right)^{1 / n},
$$

where $n$ is the number of responses $=3$.

It can be extensive to reflect the possible difference in the importance of different responses by giving weights. Where the weight $w i$ satisfies $0<w i<1$ and $w_{1}+w_{2}+\cdots+w_{n}=1$ :

$$
\mathrm{DG}=\left(d_{1}^{w_{1}} \times d_{2}^{w_{2}} \times \cdots \times d_{n}^{w_{n}}\right)^{1 / n} .
$$

Table 7 shows the constraints of input parameters and that of responses and the goal and weights assigned to each parameter. Table 8 shows the values of 36 levels of combinations of process parameters that will give a high value of composite desirability (ranged from 0.79 to 0.94 ). Table 8 gives the optimal input process parametric setting for multiresponse optimization.

The confirmatory experiments were performed to validate the optimal input parametric setting for MRR, EWR, and surface roughness. The observed experimental results for performance measures are material removal rate $=$
$18.83 \mathrm{~mm}^{3} / \mathrm{min}$, electrode wear rate $=6.81 \mathrm{~mm}^{3} / \mathrm{min}$, and surface roughness $=4.86 \mu \mathrm{m}$. Table 9 shows the error percentage for experimental validation of the developed models for the responses with optimal parametric setting. From the analysis, it was concluded that the error between experimental and predicted values for MRR, EWR, and surface roughness are $6.98 \%, 5.90 \%$, and $7.48 \%$, respectively. Obviously, this confirms excellent reproducibility of the experimental conclusions.

3.6. Conclusion. In this study, the influence of significant EDM process parameters like peak current, pulse on time and pulse off time on response parameters like MRR, TWR, and SR while machining the EN 353 steel has been investigated. Experimentations were planed and conducted according to the response surface methods. Analysis of variance (ANOVA) was applied to study the significance on performance measures. The major conclusions drawn from this study are as follows.

(1) EDM is an adequate process to machine EN 353 steel with good MRR and TWR.

(2) The MRR obtained is ranged between $14 \mathrm{~mm}^{3} / \mathrm{min}$ and $29.03 \mathrm{~mm}^{3} / \mathrm{min}$. The maximum MRR was obtained when the parameters were set at pulse on time $=580 \mu \mathrm{s}$, pulse off time $=16 \mu \mathrm{s}$, and peak current $=45 \mathrm{~A}$.

(3) The minimum EWR $3.5 \mathrm{~mm}^{3} / \mathrm{min}$ was obtained when the parameters were set at pulse on time $=100 \mu \mathrm{s}$, pulse off time $=28 \mu \mathrm{s}$, and peak current $=25 \mathrm{~A}$. The interaction effect of pulse on time and pulse off time influences the most.

(4) SR while EDMing the EN 353 steel alloy is majorly influenced by all the three factors peak current, pulse on time, and pulse off time. In order to obtain better surface finish set peak current and pulse on time at low levels.

(5) The optimized values of MRR, TWR, and SR are $17.62 \mathrm{~mm}^{3} / \mathrm{min}, 6.47 \mathrm{~mm}^{3} / \mathrm{min}$, and $4.54 \mu \mathrm{m}$, respectively, obtained at the optimum setting of parameters pulse on time, pulse off time, and peak current at $100.77 \mu \mathrm{s}, 25.43 \mu \mathrm{s}$, and $45 \mathrm{~A}$, respectively.

(6) The confirmation tests showed that the error between experimental and predicted values of MRR, TWR, and SR are $6.98 \%$ and $5.90 \%, 7.48 \%$ and $5.66 \%$, and $2.14 \%$ and $2.87 \%$, respectively. 
TABLE 8: Favorable solutions for responses with varying weights.

\begin{tabular}{|c|c|c|c|c|c|c|c|c|c|c|}
\hline \multirow{2}{*}{ Serial number } & \multirow{2}{*}{$T_{\mathrm{ON}}$} & \multirow{2}{*}{$T_{\mathrm{OFF}}$} & \multirow{2}{*}{$I_{P}$} & \multirow{2}{*}{ MRR } & \multirow{2}{*}{ EWR } & \multirow{2}{*}{ SR } & \multirow{2}{*}{ Desirability } & \multicolumn{3}{|c|}{ Weight of } \\
\hline & & & & & & & & MRR & EWR & SR \\
\hline 1 & 579.99 & 11.03 & 5 & 28.03 & 11.99 & 9.18 & 0.87 & 0.8 & 0.1 & 0.1 \\
\hline 2 & 503.2 & 4 & 45 & 26.33 & 8.86 & 9.45 & 0.84 & 0.7 & 0.2 & 0.1 \\
\hline 3 & 524.61 & 9.49 & 5 & 26.37 & 11.79 & 8.48 & 0.83 & 0.7 & 0.1 & 0.2 \\
\hline 4 & 480.40 & 4 & 45 & 25.41 & 8.50 & 9.18 & 0.83 & 0.6 & 0.3 & 0.1 \\
\hline 5 & 448.23 & 4 & 45 & 24.17 & 7.99 & 8.81 & 0.80 & 0.6 & 0.2 & 0.2 \\
\hline 6 & 480.14 & 4 & 45 & 25.41 & 8.49 & 9.18 & 0.83 & 0.6 & 0.1 & 0.3 \\
\hline 7 & 442.03 & 4.95 & 45 & 23.90 & 7.8 & 8.75 & 0.82 & 0.5 & 0.4 & 0.1 \\
\hline 8 & 413.98 & 4.01 & 45 & 22.91 & 7.45 & 8.43 & 0.80 & 0.5 & 0.3 & 0.2 \\
\hline 9 & 433.73 & 11.21 & 5 & 22.42 & 9.60 & 7.41 & 0.79 & 0.5 & 0.2 & 0.3 \\
\hline 10 & 385.81 & 5.97 & 5 & 22.57 & 11.37 & 6.82 & 0.80 & 0.5 & 0.1 & 0.4 \\
\hline 11 & 383.97 & 6.36 & 45 & 21.85 & 6.89 & 8.13 & 0.82 & 0.4 & 0.5 & 0.1 \\
\hline 12 & 357.69 & 7.05 & 45 & 21.01 & 6.48 & 7.86 & 0.81 & 0.4 & 0.4 & 0.2 \\
\hline 13 & 100 & 26.88 & 45 & 17.81 & 7.11 & 4.36 & 0.79 & 0.4 & 0.3 & 0.3 \\
\hline 14 & 100.05 & 27.58 & 45 & 17.90 & 7.44 & 4.27 & 0.80 & 0.4 & 0.2 & 0.4 \\
\hline 15 & 100.03 & 27.53 & 44.89 & 17.88 & 7.40 & 4.27 & 0.82 & 0.4 & 0.1 & 0.5 \\
\hline 16 & 301.58 & 8.03 & 45 & 19.42 & 5.61 & 7.30 & 0.84 & 0.3 & 0.6 & 0.1 \\
\hline 17 & 275.53 & 9.74 & 45 & 18082 & 5.29 & 7.03 & 0.82 & 0.3 & 0.5 & 0.2 \\
\hline 18 & 100.01 & 23.06 & 45 & 17.29 & 5.50 & 4.80 & 0.82 & 0.3 & 0.4 & 0.3 \\
\hline 19 & 100 & 26.26 & 45 & 17.74 & 6.87 & 4.42 & 0.83 & 0.3 & 0.3 & 0.4 \\
\hline 20 & 100 & 27.50 & 45 & 17.89 & 7.40 & 4.27 & 0.84 & 0.3 & 0.2 & 0.5 \\
\hline 21 & 109.20 & 28 & 45 & 18.01 & 7.79 & 4.27 & 0.86 & 0.3 & 0.1 & 0.6 \\
\hline 22 & 100 & 16.39 & 45 & 16.38 & 3.49 & 5.34 & 0.87 & 0.2 & 0.7 & 0.1 \\
\hline 23 & 100 & 16.85 & 45 & 16.44 & 3.60 & 5.31 & 0.87 & 0.2 & 0.6 & 0.2 \\
\hline 24 & 100 & 18.99 & 45 & 16.73 & 4.15 & 5.16 & 0.86 & 0.2 & 0.5 & 0.3 \\
\hline 25 & 100 & 21.81 & 45 & 17.12 & 5.04 & 4.92 & 0.86 & 0.2 & 0.4 & 0.4 \\
\hline 26 & 100 & 25.66 & 45 & 17.64 & 6.56 & 4.51 & 0.87 & 0.2 & 0.3 & 0.5 \\
\hline 27 & 100.01 & 27.50 & 45 & 17.89 & 7.40 & 4.28 & 0.88 & 0.2 & 0.2 & 0.6 \\
\hline 28 & 100.05 & 27.52 & 45 & 17.90 & 7.41 & 4.22 & 0.90 & 0.2 & 0.1 & 0.7 \\
\hline 29 & 100 & 16.38 & 45 & 16.38 & 3.49 & 5.34 & 0.93 & 0.1 & 0.8 & 0.1 \\
\hline 30 & 100.01 & 16.38 & 45 & 16.38 & 3.49 & 5.34 & 0.92 & 0.1 & 0.7 & 0.2 \\
\hline 31 & 100 & 16.38 & 45 & 16.38 & 3.50 & 5.34 & 0.92 & 0.1 & 0.6 & 0.3 \\
\hline 32 & 100 & 16.38 & 45 & 16.38 & 3.50 & 5.34 & 0.91 & 0.1 & 0.5 & 0.4 \\
\hline 33 & 100 & 16.84 & 45 & 16.84 & 4.38 & 5.01 & 0.91 & 0.1 & 0.4 & 0.5 \\
\hline 34 & 100 & 17.53 & 45 & 17.53 & 6.22 & 4.60 & 0.91 & 0.1 & 0.3 & 0.6 \\
\hline 35 & 100.01 & 17.89 & 45 & 17.89 & 7.40 & 4.27 & 0.92 & 0.1 & 0.2 & 0.7 \\
\hline 36 & 100.04 & 17.89 & 44.97 & 17.89 & 7.40 & 4.27 & 0.94 & 0.1 & 0.1 & 0.8 \\
\hline
\end{tabular}

TABLE 9: Confirmatory experiments.

\begin{tabular}{lccccccccc}
\hline \multirow{2}{*}{ Serial number } & \multirow{2}{*}{$T_{\mathrm{ON}}$} & \multirow{2}{*}{$T_{\mathrm{OFF}}$} & $I_{P}$ & \multicolumn{2}{c}{ MRR } & \multicolumn{2}{c}{ EWR } & \multicolumn{2}{c}{ SR } \\
& & & & Actual & Error \% & Actual & Error \% & Actual & Error \% \\
\hline 1 & 100 & 25.37 & 45.00 & 18.83 & 6.98 & 6.81 & 5.90 & 4.86 & 7.48 \\
2 & 100.94 & 25.58 & 45.00 & 18.64 & 5.66 & 6.68 & 2.14 & 4.65 & 2.87 \\
\hline
\end{tabular}




\section{Conflict of Interests}

The authors declare that there is no conflict of interests regarding the publication of this paper.

\section{References}

[1] S. Rajesha, A. K. Sharma, and P. Kumar, "On electro discharge machining of inconel 718 with hollow tool," Journal of Materials Engineering and Performance, vol. 21, no. 6, pp. 882-891, 2012.

[2] S. R. Nimbhorkar and B. D. Deshmukh, "Effect of case hardening treatment on the structure and properties of automobile gears," International Journal of Pure and Applied Research in Engineering and Technology, vol. 1, no. 8, pp. 317-325, 2013.

[3] A. Bensely, S. Venkatesh, D. Mohan Lal, G. Nagarajan, A. Rajadurai, and J. Boland, "Determination of poisson's ratio of cryogenically treated case carburized steel (En 353) by using ultrasonic technique," in Proceedings of the International Conference on Manufacturing Science and Technology, pp. 361$365,2006$.

[4] S. Murugesan and K. Balamurugan, "Optimization by Grey relational analysis of EDM parameters in machining Al- $15 \% \mathrm{SiC}$ MMC using multihole electrode," Journal of Applied Sciences, vol. 12, no. 10, pp. 963-970, 2012.

[5] S. Singh and M. Verma, "A parametric optimization of electric discharge drill machine using taguchi approach," Journal of Engineering, Computers \& Applied Sciences, vol. 1, no. 3, pp. 3948, 2012.

[6] F. L. Amorim and W. L. Weingaertner, "Die-sinking electrical discharge machining of a high-strength copper-based alloy for injection molds," Journal of the Brazilian Society of Mechanical Sciences and Engineering, vol. 26, no. 2, pp. 137-144, 2004.

[7] O. Yilmaz, A. T. Bozdana, M. A. Okka, and I. H. Filiz, "A comparative investigation of the effects of single and multichannel electrodes in EDM fast hole drilling of aerospace alloys," in Proceedings of the 5th International Conference and Exhibition on Design and Production of Machines and Dies/ Molds, Kusadasi, Turkey, June 2009.

[8] R. Manikandan and R. Venkatesan, "Optimizing the machining parameters of micro-EDM for Inconel 718," Journal of Applied Sciences, vol. 12, no. 10, pp. 971-977, 2012.

[9] N. Sharma, R. Khanna, and R. D. Gupta, "Parametric optimization on WEDM for HSLA by integrated RSM and genetic algorithm," in AEMDS, 2014.

[10] G. Kibria, B. R. Sarkar, B. B. Pradhan, and B. Bhattacharyya, "Comparative study of different dielectrics for micro-EDM performance during microhole machining of Ti-6Al-4V alloy," International Journal of Advanced Manufacturing Technology, vol. 48, no. 5-8, pp. 557-570, 2010.

[11] M. S. Azad and A. B. Puri, "Simultaneous optimisation of multiple performance characteristics in micro-EDM drilling of titanium alloy," International Journal of Advanced Manufacturing Technology, vol. 61, no. 9-12, pp. 1231-1239, 2012.

[12] A. D. Patel, M. C. Parekh, B. B. Patel, and B. B. Patel, "Multiobjective optimisation of die sinking electro discharge machining process using Taguchi," International Journal of Engineering Research and Applications, vol. 2, no. 6, pp. 1367-1371, 2012.

[13] P. Janmanee and A. Muttamara, "Optimization of electrical discharge machining of composite 90WC-10Co base on taguchi approach," European Journal of Scientific Research, vol. 64, no. 3, pp. 426-436, 2011.
[14] M. Boujelbene, E. Bayraktar, W. Tebni, and S. Ben Salem, "Influence of machining parameters on the surface integrity in electrical discharge machining," International Scientific Journal, vol. 37, no. 2, 2009.

[15] A. K. Khanra, S. Patra, and M. M. Godkhindi, "Electrical discharge machining studies on reactive sintered FeAl," Bulletin of Materials Science, vol. 29, no. 3, pp. 277-280, 2006.

[16] H. K. Kansal, S. Singh, and P. Kumar, "Parametric optimization of powder mixed electrical discharge machining by response surface methodology," Journal of Materials Processing Technology, vol. 169, no. 3, pp. 427-436, 2005.

[17] T. Y. Tai and S. J. Lu, "Improving the fatigue life of electrodischarge-machined SDK11 tool steel via the suppression of surface cracks," International Journal of Fatigue, vol. 31, no. 3, pp. 433-438, 2009.

[18] A. Kumar, V. Kumar, and J. Kumar, "Investigation of machining parameters and surface integrity in wire electric discharge machining of pure titanium," Proceedings of the Institution of Mechanical Engineers B: Journal of Engineering Manufacture, vol. 227, no. 7, pp. 972-992, 2013.

[19] A. T. Bozdana, O. Yilmaz, M. A. Okka, and İ. H. Filiz, "A comparative experimental study on fast hole EDM of Inconel 718 and Ti-6Al-4V," in Proceedings of the 5th International Conference and Exhibition on Design and Production of MACHINES and DIES/MOLDS, 2009.

[20] U. Çaydaş and A. Hasçalik, "Modeling and analysis of electrode wear and white layer thickness in die-sinking EDM process through response surface methodology,' International Journal of Advanced Manufacturing Technology, vol. 38, no. 11-12, pp. 1148-1156, 2008.

[21] N. Sharma, R. Khanna, and R. Gupta, "Multi quality characteristics of WEDM process parameters with RSM," Procedia Engineering, vol. 64, pp. 710-719, 2013.

[22] N. Sharma, R. Khanna, R. D. Gupta, and R. Sharma, "Modeling and multiresponse optimization on WEDM for HSLA by RSM," International Journal of Advanced Manufacturing Technology, vol. 67, no. 9-12, pp. 2269-2281, 2013.

[23] P. Gupta, R. Khanna, R. D. Gupta, and N. Sharma, "Effect of process parameters on kerf width in WEDM for HSLA using response surface methodology," Journal of Engineering Technology, vol. 2, no. 1, pp. 1-5, 2012.

[24] A. Kumar, V. Kumar, and J. Kumar, "Multi-response optimization of process parameters based on response surface methodology for pure titanium using WEDM process," International Journal of Advanced Manufacturing Technology, vol. 68, no. 912, pp. 2645-2668, 2013.

[25] D. C. Whittinghill, "A note on the robustness of Box-BEHnken designs to the unavailability of data," Metrika, vol. 48, no. 1, pp. 49-52, 1998.

[26] K. Ojha, R. K. Garg, and K. K. Singh, "MRR improvement in sinking electrical discharge machining: a review," Journal of Minerals \& Materials Characterization \& Engineering, vol. 9, no. 8, pp. 709-739, 2010.

[27] N. Kumar, L. Kumar, H. Tewatia, and R. Yadav, "Comparative study for MRR on die-sinking EDM using electrode of copper \& graphite," International Journal of Advanced Technology \& Engineering Research, vol. 2, no. 2, pp. 170-174, 2012.

[28] A. Kumar, V. Kumar, and J. Kumar, "Investigation of microstructure and element migration for rough cut surface of pure titanium after WEDM," International Journal of Microstructure and Materials Properties, vol. 8, no. 4-5, pp. 343-356, 2013. 

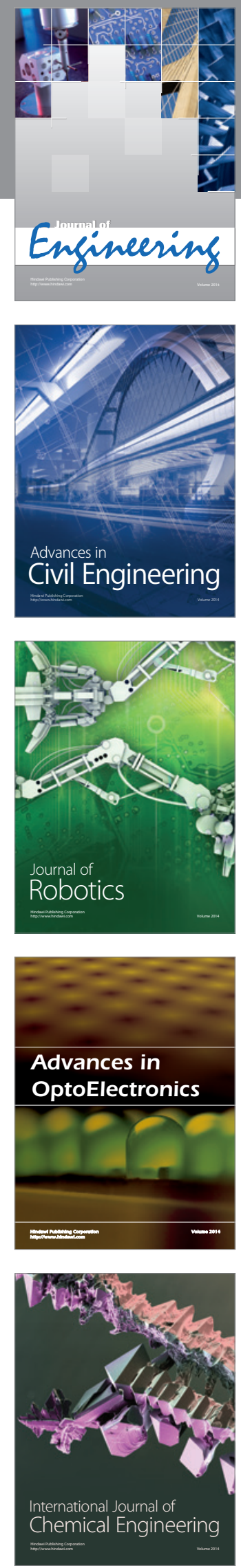

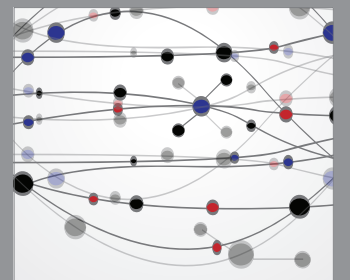

The Scientific World Journal
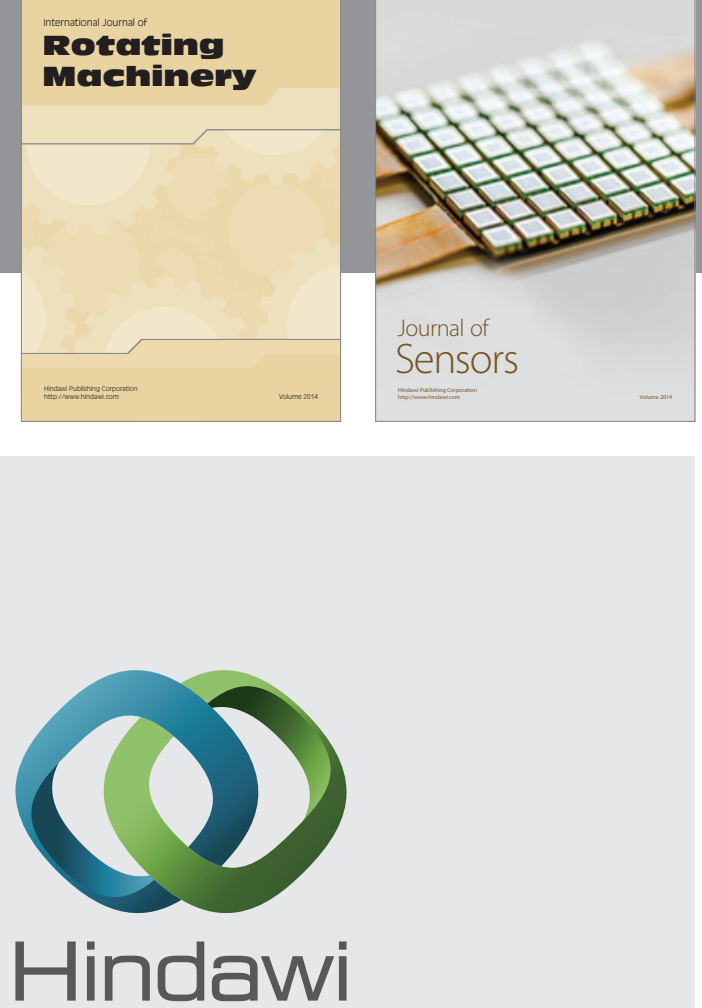

Submit your manuscripts at http://www.hindawi.com
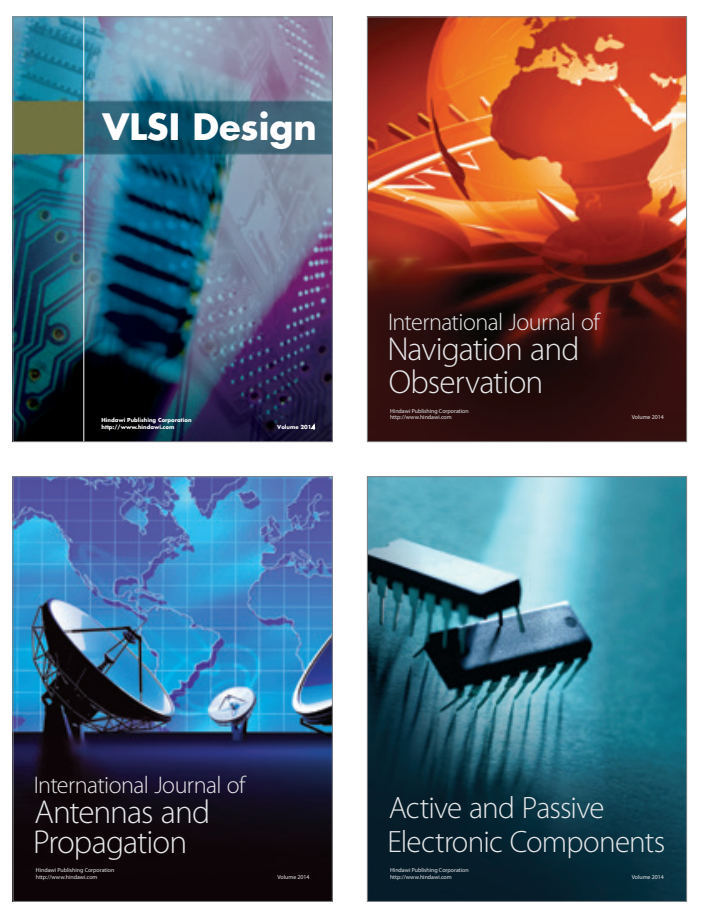
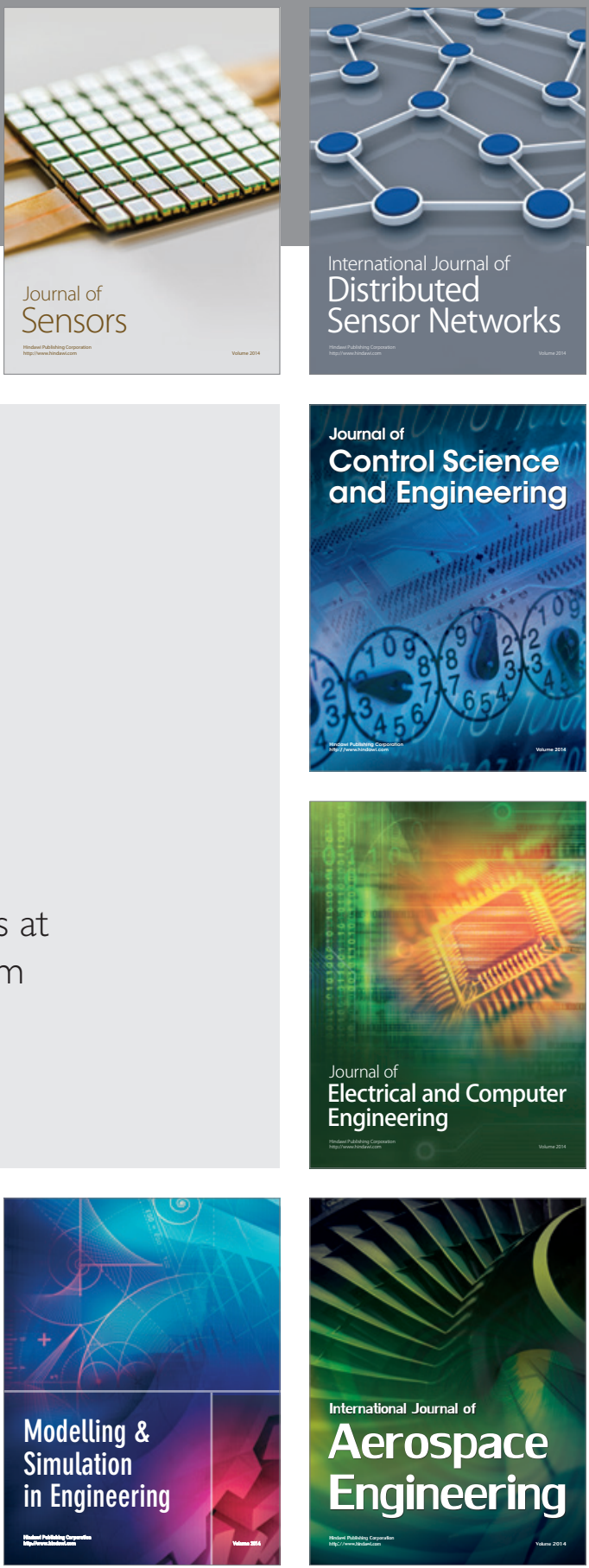

Journal of

Control Science

and Engineering
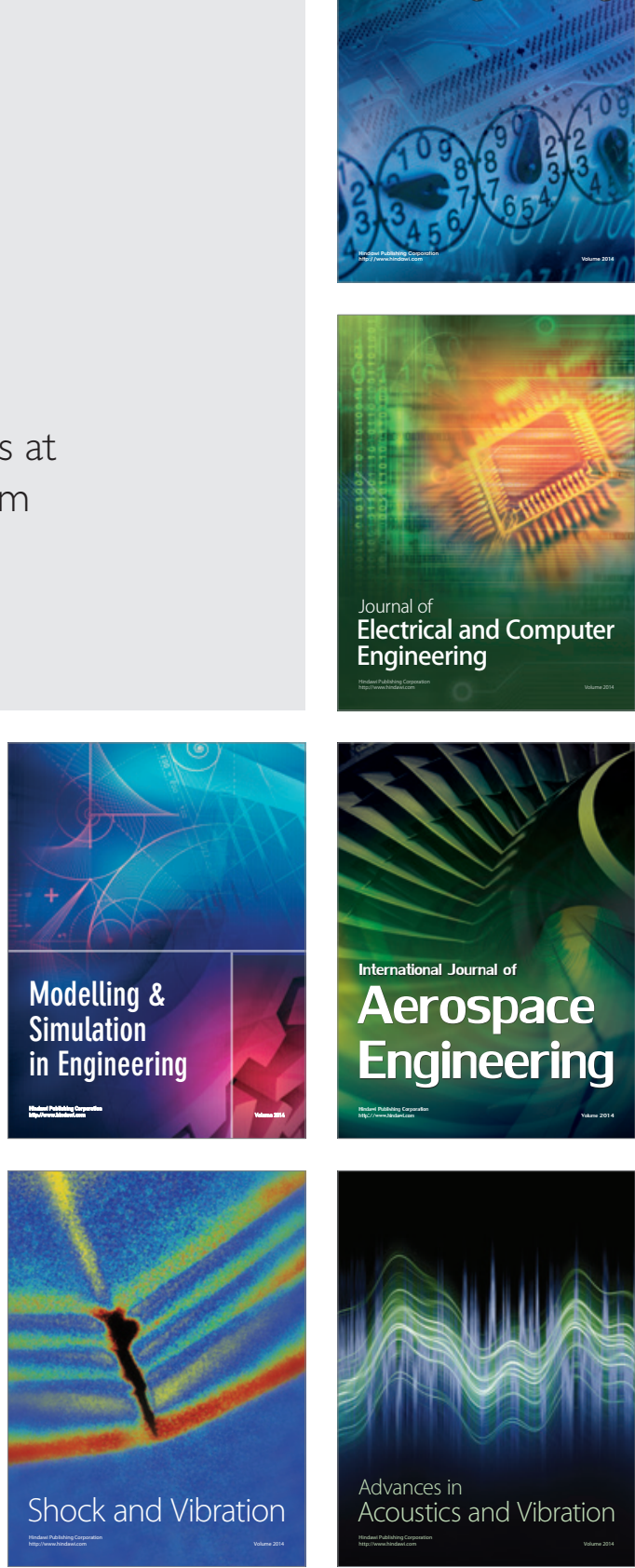